\title{
How Better Monetary Statistics Could Have Signaled the Financial Crisis
}

\author{
By \\ William A. Barnett, University of Kansas \\ and \\ Marcelle Chauvet, University of California at Riverside
}

June 15,2010

\begin{abstract}
This paper explores the disconnect of Federal Reserve data from index number theory. A consequence could have been the decreased systemic-risk misperceptions that contributed to excess risk taking prior to the housing bust. We find that most recessions in the past 50 years were preceded by more contractionary monetary policy than indicated by simple-sum monetary data. Divisia monetary aggregate growth rates were generally lower than simple-sum aggregate growth rates in the period preceding the Great Moderation, and higher since the mid 1980s. Monetary policy was more contractionary than likely intended before the 2001 recession and more expansionary than likely intended during the subsequent recovery.
\end{abstract}

KEY WORDS: Measurement error, monetary aggregation, Divisia index, aggregation, monetary policy, index number theory, financial crisis, great moderation, Federal Reserve.

JEL CLASSIFICATION CODE: E40, E52, E58, C43, E32

\section{Introduction}

\subsection{The Great Moderation and the Current Crisis}

Over the past couple of decades, there has been an increasingly widely accepted view that monetary policy had dramatically improved. In fact, some attribute this as the cause of the "Great Moderation" in the economy's dynamics, by which output volatility had decreased substantially since the mid 1980s. On Wall Street, that widely believed view was called the "Greenspan Put." Even Lucas (2003), who has become a major authority on the business cycle through his path-breaking publications in that area (see, e.g., Lucas 1987), had concluded that economists should redirect their efforts towards long term fiscal policy aimed at increasing economic growth. Since central banks were viewed as having become very successful at damping the business cycle, he concluded that possible welfare gains from further moderations in the business cycle were small.

It is not our intent to take a position on what the actual causes of that low volatility had been, to argue that the Great Moderation's causes are gone, or that the low volatility that preceded the current crisis will not return. Rather our objective is to investigate whether changes in monetary aggregates were in line with intended monetary policy before and during the Great Moderation, and if there was a significant change in the latter period that would legitimate assertions regarding a lower risk of future recessions since the mid 1980s. We provide years of empirical evidence that do not support the view that 
monetary policy had significantly improved before or after the Great Moderation and, mostly important, around recessions. We also argue that this lack of support was not factored into the decisions of many decision makers, who had increased their leverage and risk-taking to levels now widely viewed as having been excessive. This conclusion will be more extensively documented in Barnett (2011).

A popular media view about the recent crisis is that the firms and households that got into trouble are to blame. According to much of the popular press and many politicians, the Wall Street professionals and bankers are to blame for having taken excessive, self-destructive risk out of "greed." But who are the Wall Street professionals who decided to increase their leverage to 35:1? As is well known, they comprise a professional elite, including some of the country's most brilliant financial experts. Is it reasonable to assume that such people made foolish, self-destructive decisions out of "greed"? If so, how should we define "greed" in economic theory, so that we can test the hypothesis? What about the mortgage lenders at the country's largest banks? Were their decisions dominated by greed and selfdestructive behavior? Economic theory is not well designed to explore such hypotheses, and if the hypotheses imply irrational behavior, how would we reconcile a model of irrational behavior with the decisions of some of the country's most highly qualified experts in finance? Similarly how would one explain the fact that the Supervision and Regulation Division of the Federal Reserve Board's staff ignored the high risk loans being made by banks? Were they simply not doing their job, or perhaps did they too believe that systemic risk had declined, so that increased risk-taking by banks was viewed to be prudent?

To find the cause of the crisis, it is necessary to look carefully at the data that produced the impression that the business cycle had been moderated permanently to a level supporting greater risk taking by investors and lenders. To find the causes of the "Great Moderation," central bank policy may be the wrong place to look. The federal funds rate has been the instrument of policy in the U.S. for over a half century, and the Taylor rule, rather than being an innovation in policy design, is widely viewed as fitting historic Federal Reserve behavior for a half century. ${ }^{1}$ The Great Moderation in real business cycle

\footnotetext{
${ }^{1}$ Although some other countries have adopted inflation targeting, Federal Reserve's policy innovation in recent years, if any, has most commonly been characterized as New Keynesian with a Taylor rule. The Greenspan Put has most commonly been characterized as an asymmetric interest rate policy more aggressive on the downside than the upside, but that was not without precedent.
} 
volatility may have been produced by events unrelated to monetary policy, such as the growth of U. S. productivity, improved technology and communications permitting better planning of inventories and management, financial innovation, the rise of China as a holder of American debt and supplier of low priced goods, perhaps permitting an expansionary monetary policy that otherwise might have been inflationary, or even a decrease in the size and volatility of shocks, known as the "good luck" hypothesis. This paper provides an overview of some of the data problems that produced the misperceptions of superior monetary policy. The focus of this paper is not on what did cause the Great Moderation, but rather on the possible causes of the misperception that there was a permanent reduction in systemic risk associated with improved monetary policy. This paper documents the fact that the quality of Federal Reserve data in recent years has been poor, disconnected from reputable index number theory, and inconsistent with competent accounting principles. It is postulated that these practices could have contributed to the misperceptions of a permanent decrease in systemic risk.

This paper's emphasis is on econometric results displayed in graphics. In all of the illustrations in this paper, the source of the misperceptions is traced to data problems. We find, for example, that the largest discrepancies between microeconomic theory-based monetary aggregate (Divisia) and simple sum monetary aggregates occur during times of high uncertainty, such as around recessions or at the beginning or end of high interest rate phases. In particular, the rate of growth of Divisia monetary aggregates decrease a lot more before recessions and increase substantially more during recessions and recoveries than simple sum aggregates. In addition, we find that the rate of growth rate of Divisia monetary aggregates were generally lower than the rate of growth of simple sum aggregates in the period that preceded the Great Moderation, and higher since the mid 1980s. For the recent years, this indicates, for example, that monetary policy could have been more contractionary than intended before recessions and more expansionary than intended during the most recent recovery after the 2001 recession. There is a strain of thought that maintains that the current U.S. financial crisis was prompted by excessive money creation fueling the bubbles. The process started in early 2001, when money supply was increased substantially to minimize the economic recession that had started in March of that year. However, in contrast with previous recessions, money supply continued to be high for a few years after the recession's 
end in November 2001. In fact, money supply was high until mid 2004, after which it started decreasing slowly. The argument is that the monetary expansion during this first period led to both speculation and leveraging, especially regarding lending practices in the housing sector. This expansion is argued as having made it possible for marginal borrowers to obtain loans with lower collateral values.

On the other hand, the Federal Reserve started increasing the target value for the federal funds rate since June 2004. We find that the rate of growth of money supply as measured by Divisia monetary aggregate fell substantially more than the rate of growth of simple sum monetary aggregate. Thus, the official simple sum index could have veiled a much more contractionary policy by the Federal Reserve than intended, which also occurred prior to most recessions in the last 50 years. For the recent period, when money creation slowed, housing prices began to decline, leading many to own negative equity and inducing a wave of defaults and foreclosures.

We see no reason to believe that the Federal Reserve would have as a goal to create 'excessive' money growth. Had they known that the amount of money circulating in the economy was excessive and could generate an asset bubble, monetary policy would have been reverted long before it did. Conversely, we see no reason to believe that the Federal Reserve intended to have an excessive contractionary monetary policy before the crisis. We provide evidence indicating that data problems may have misled Federal Reserve policy to feed the bubbles with unintentionally excess liquidity and then to burst the bubbles with excessively contractionary policy. In short, in every illustration that we provide, the motives of the decision makers, whether private or public, were good. But the data were bad.

\subsection{Overview}

Barnett (1980) derived the aggregation-theoretic approach to monetary aggregation and advocated the use of the Divisia or Fisher Ideal index with user cost prices in aggregating over monetary services. Since then, Divisia monetary aggregates have been produced for many countries. ${ }^{2}$ But despite this vast

\footnotetext{
${ }^{2}$ For example, Divisia monetary aggregates have been produced for Britain (Batchelor (1989), Drake (1992), and Belongia and Chrystal (1991)), Japan (Ishida (1984)), the Netherlands (Fase (1985)), Canada (Cockerline and Murray (1981)), Australia (Hoa (1985)), and Switzerland (Yue and Fluri (1991)), among many others. More recently, Barnett (2007) has extended the theory to multilateral aggregation over different countries with potentially different currencies, and Barnett and Shu (2005) have extended to the case of risky contemporaneous interest rates, as is particularly relevant when exchange rate risk is involved. That research was particularly focused on the needs of the European Central Bank.
} 
amount of research, most central banks continue officially to supply the simple-sum monetary aggregates, which have no connection with aggregation and index number theory. In contrast, the International Monetary Fund (2008) has provided an excellent discussion of the merits of Divisia monetary aggregation, and the Bank of England publishes them officially. The European Central Bank's staff uses them in informing the Council on a quarterly basis, and the St. Louis Federal Reserve Bank provides them for the US. The simple sum monetary aggregates have produced repeated inference errors, policy errors, and needless paradoxes leading up to the most recent misperceptions about the source of the Great Moderation. In this paper, we provide an overview of that history in chronological order.

We conclude with a discussion of the most recent research in this area, which introduces state-space factor modeling into this literature. We also display the most recent puzzle regarding Federal Reserve data on nonborrowed reserves and show that the recent behavior of that data contradicts the definition of nonborrowed reserves. Far from resolving the earlier data problems, the Federal Reserve's most recent data may be the most puzzling that the Federal Reserve has ever published.

\subsection{The History}

There is a vast literature on the appropriateness of aggregating over monetary asset components using simple summation. Linear aggregation can be based on Hicksian aggregation (Hicks 1946), but that theory only holds under the unreasonable assumption that the relative user-cost prices of the services of individual money assets do not change over time. This condition implies that each asset is a perfect substitute for the others within the set of components. Simple sum aggregation is an even more severe special case of that highly restrictive linear aggregation, since simple summation requires that the coefficients of the linear aggregator function all be the same. This, in turn, implies that the constant usercost prices among monetary assets be exactly equal to each other. Not only must the assets be perfect substitutes, but must be perfect one-for-one substitutes --- i.e., must be indistinguishable assets, with one unit of each asset being a perfect substitute for exactly one unit of each of the other assets.

In reality, financial assets provide different services, and each such asset yields its own particular rate of return. As a result, the user costs, which measure foregone interest and thereby opportunity cost, 
are not constant and are not equal across financial assets. The relative user-cost prices of U.S. monetary assets fluctuate considerably. For example, the interest rates paid on many monetary assets are not equal to the zero interest rate paid on currency. These observations have motivated serious concerns about the reliability of the simple-sum aggregation method, which has been disreputable in the literature on index number theory and aggregation theory for over a century. In addition, an increasing number of imperfectly substitutable short-term financial assets have emerged in recent decades. Since monetary aggregates produced from simple summation do not accurately measure the quantities of monetary services chosen by optimizing agents, shifts in the series can be spurious and can produce erroneous appearance of instability of structural functions containing monetary services variables.

Microeconomic aggregation theory offers an appealing alternative approach to the measurement of money, compared to the atheoretical simple-sum method. The quantity index under the aggregationtheoretic approach extracts and measures the income effects of changes in relative prices and is invariant to substitution effects, which do not alter utility and thereby do not alter perceived services received. The simple-sum index, on the other hand, does not distinguish between income and substitution effects and thereby confounds together substitution effects with actual monetary services received. The aggregationtheoretic monetary aggregator function, which correctly internalizes substitution effects, can be tracked accurately by the Divisia quantity index, constructed by using expenditure shares as the component growth-rate weights. Barnett $(1978,1980)$ derived the formula for the user-cost price of a monetary asset, needed in computation of the Divisia index's share weights, and thereby originated the Divisia monetary aggregates. The growth rate weights resulting from this approach are different across assets, depending on all of the quantities and interest rates in each share, and those weights can be time-varying at each point in time. For a detailed description of the theory underlying this construction, see Barnett (1982, 1987).

The user-cost prices are foregone interest rates, with foregone interest measured as the difference between the rate of return on a pure investment, called the benchmark asset, and the own rate of return on the component asset. It is important to understand that the direction in which an asset's growth-rate weight will change with an interest rate change is not predictable in advance. Consider Cobb-Douglas 
utility. Its shares are independent of relative prices, and hence of the interest rates within the component user-cost prices. For other utility functions, the direction of the change in shares with a price change, or equivalently with an interest rate change, depends upon whether the own price elasticity of demand exceeds or is less than -1 . In elementary microeconomic theory, this often overlooked phenomenon produces the famous "diamonds versus water paradox" and is the source of most of the misunderstandings of the Divisia monetary aggregates' weighting, as explained by Barnett (1983).

Several authors have studied the empirical properties of the Divisia index compared with the simple sum index. The earliest comparisons are in Barnett (1982) and Barnett, Offenbacher, and Spindt (1984). Barnett and Serletis (2000) collect together and reprint seminal journal articles from this literature. ${ }^{3}$ Barnett (1997) has documented the connection between the well-deserved decline in the policy-credibility of monetary aggregates and the defects that are peculiar to simple sum aggregation.

The most recent research in this area is Barnett, Chauvet, and Tierney (2009), who compare the different dynamics of simple-sum monetary aggregates and the Divisia indexes, not only over time, but also over the business cycle and across high and low inflation and interest rate phases. Information about the state of monetary growth becomes particularly relevant for policymakers, when inflation enters a high-growth phase or the economy begins to weaken. Factor models with regime switching have been widely used to represent business cycles (see e.g., Chauvet 1998, 2005, Chauvet and Piger 2008), but without relationship to aggregation theory. Barnett, Chauvet, and Tierney's model differs from the literature as the focus is not only on the estimated common factor, but on the idiosyncratic terms that reflect the divergences between the simple sum and Divisia monetary aggregate in a manner relevant to aggregation theory.

\section{Monetary Aggregation Theory}

\subsection{Monetary Aggregation}

Aggregation theory and index-number theory have been used to generate official governmental data

\footnotetext{
${ }^{3}$ More recent examples include Belongia (1996), Belongia and Ireland (2006), and Schunk (2001). The comprehensive survey found in Barnett and Serletis (2000) has been updated to include more recent article reprints in Barnett and Chauvet (2010). Other overviews of published theoretical and empirical results in this literature are available in Barnett, Fisher, and Serletis (1992) and Serletis (2006).
} 
since the 1920s. For example, the Bureau of Economic Analysis uses the Fisher ideal index in producing the national accounts. One exception still exists. The monetary quantity aggregates and interest rate aggregates officially supplied by many central banks are not aggregation-theoretic index numbers, but rather are the simple unweighted sums of the component quantities and the quantity-weighted or arithmetic averages of interest rates. The predictable consequence has been induced instability of money demand and supply functions and a series of 'puzzles' in the resulting applied literature. In contrast, the Divisia monetary aggregates, originated by Barnett $(1980 ; 1987)$ are derived directly from economic index-number theory.

Data construction and measurement procedures imply the theory that can rationalize the aggregation procedure. The assumptions implicit in the data construction procedures must be consistent with the assumptions made in producing the models within which the data are nested. Unless the theory is internally consistent, the data and its applications are incoherent. Without that coherence between aggregator function structure and the econometric models within which the aggregates are embedded, stable structure can appear to be unstable. This phenomenon has been called the 'Barnett critique' by Chrystal and MacDonald (1994) and in a very important recent paper by Belongia and Ireland (2010).

\subsection{Aggregation Theory versus Index Number Theory}

The exact aggregates of microeconomic aggregation theory depend on unknown aggregator functions, which typically are utility, production, cost, or distance functions. Such functions must first be econometrically estimated. Hence the resulting exact quantity and price indexes become estimator and specification dependent. This dependency is troublesome to governmental agencies, which therefore view aggregation theory as a research tool rather than a data construction procedure.

Statistical index-number theory, on the other hand, provides nonparametric indexes which are computable directly from quantity and price data, without estimation of unknown parameters. Within the literature on aggregation theory, such index numbers depend jointly on prices and quantities in two periods, but not on unknown parameters. In a sense, index number theory trades joint dependence on 2 period prices and quantities for dependence on unknown parameters. Examples of such statistical index 
numbers are the Laspeyres, Paasche, Divisia, Fisher ideal, and Törnqvist indexes.

The formerly loose link between index number theory and aggregation theory was tightened, when Diewert (1976) defined the class of second-order 'superlative' index numbers, which track any unknown aggregator function up to the second order. Statistical index number theory became part of microeconomic theory, as economic aggregation theory had been for decades. Statistical index numbers are judged by their non-parametric tracking ability to the aggregator functions of aggregation theory.

For decades, the link between statistical index-number theory and microeconomic aggregation theory was weaker for aggregating over monetary quantities than for aggregating over other goods and asset quantities. Once monetary assets began yielding interest, monetary assets became imperfect substitutes for each other, and the 'price' of monetary-asset services was no longer clearly defined. That problem was solved by Barnett $(1978 ; 1980)$ derivation of the formula for the user cost of demanded monetary services. ${ }^{4}$

\subsection{The Economic Decision}

Consider a decision problem over monetary assets. The decision problem will be defined in the simplest manner that renders the relevant literature on economic aggregation immediately applicable. ${ }^{5}$ Initially we shall assume perfect certainty.

Let $\mathbf{m}_{t}{ }^{\prime}=\left(m_{1 t}, m_{2 t}, \ldots, m_{n t}\right)$ be the vector of real balances of monetary assets during period $t$, let $\boldsymbol{r}_{t}$ be the vector of nominal holding-period yields for monetary assets during period $t$, and let $R_{t}$ be the one period holding yield on the benchmark asset during period $t$. The benchmark asset is defined to be a pure investment that provides no services other than its yield, $R_{t}$, so that the asset is held solely to accumulate wealth. Thus, $R_{t}$ is the maximum holding-period yield in the economy during period $t$.

Let $y_{t}$ be the real value of total budgeted expenditure on monetary services during period $t$. Under

\footnotetext{
${ }^{4}$ Subsequently Barnett (1987) derived the formula for the user cost of supplied monetary services. A regulatory wedge can exist between the demand and supply-side user costs, if non-payment of interest on required reserves imposes an implicit tax on banks. Another excellent source on the supply side is Hancock (1991), who correctly produced the implicit tax on banks formula.

${ }^{5}$ Our research in this paper is not dependent upon this simple decision problem, as shown by Barnett (1987), who proved that the same aggregator function and index number theory applies, regardless of whether the initial model has money in the utility function, or money in a production function, or neither, so long as there is intertemporal separability of structure and certain assumptions are satisfied for aggregation over economic agents. The aggregator function is the derived function that has been shown in general equilibrium always to exist, if money has positive value in equilibrium, regardless of the motive for holding money.
} 
conventional assumptions, the conversion between nominal and real expenditure on the monetary services

of one or more assets is accomplished using the true cost of living index, $p_{t}^{*}=p_{t}^{*}\left(\mathbf{p}_{t}\right)$, on consumer

goods, where the vector of consumer goods prices is $\mathbf{p}_{\mathrm{t}}{ }^{6}$ The optimal portfolio allocation decision is:

maximize $u\left(\mathbf{m}_{t}\right)$

subject to $\boldsymbol{\pi}_{t}{ }^{\prime} \mathbf{m}_{t}=\mathrm{y}_{\mathrm{t}}$

where $\boldsymbol{\pi}_{t}{ }^{\prime}=\left(\pi_{l t}, \ldots, \pi_{n t}\right)$ is the vector of monetary-asset real user costs, with

$$
\pi_{i t}=\frac{R_{t}-r_{i t}}{1+R_{t}} .
$$

The function $u$ is the decision maker's utility function, assumed to be monotonically increasing and strictly concave. ${ }^{8}$

Let $\mathbf{m}_{t}^{*}$ be derived by solving decision (1). Under the assumption of linearly homogeneous utility, the exact monetary aggregate of economic theory is the utility level associated with holding the portfolio, and hence is the optimized value of the decision's objective function:

$$
M_{t}=u\left(\mathbf{m}_{t}^{*}\right)
$$

\subsection{The Divisia Index}

Although equation (3) is exactly correct, it depends upon the unknown function, $u$. Nevertheless,

\footnotetext{
${ }^{6}$ The multilateral open economy extension is available in Barnett (2007).

${ }^{7}$ There is a long history regarding the "price of money." Keynes and the classics were divided about whether it was the inflation rate of "the rate of interest." The latter would be correct for noninterest bearing money in continuous time. In that case, as can be seen from equation (2), the user cost becomes $R_{t}$. More recently, Diewert (1974) acquired the formula relevant to discrete time for noninterest bearing money, $R_{t} /\left(1+R_{t}\right)$. Perhaps the first to recognize the relevance of the opportunity cost, $R_{t}-r_{t}$, for interest bearing money was Hutt (1963, p. 92, footnote), and he advocated what later become known as the CE index derived by Rotemberg, Poterba, and Driscoll (1995). Friedman and Schwartz (1970, pp. 151-152) document many attempts by Friedman's students to determine the user cost formula and apply index number theory to monetary aggregation). But that work preceded the user cost derivation by Barnett and the work of Diewert () on superlative index number theory. Those attempts were not based on valid user cost formulas or modern index numbers. The best known initial attempt to use aggregation theory for monetary aggregation was by Chetty (1969). But he used an incorrect user cost formula, which unfortunately was adopted by many other economists in subsequent research in monetary aggregation. Through analogous economic reasoning, Donovan (1978) acquired the correct real user cost formula, (2). As a result of the confusion produced by the competing user cost formulas generated from economic reasoning, application to monetary aggregation was hindered until Barnett () formally derived the formula by the normal method of proof using the sequence of flow of funds identies in the relevant dynamic programming problem. Regarding that formal method of proof, see Deaton and Muellbauer (1980). Barnett's proof and his derivation within an internally consistent aggregation theoretic framework marked the beginning of the modern literature on monetary aggregation.

${ }^{8}$ To be an admissible quantity aggregator function, the function $u$ must be weakly separable within the consumer's complete utility function over all goods and services. Producing a reliable test for weak separability is the subject of much intensive research, most recently by Barnett and Peretti (2009). If $y_{t}$ were nominal, then the user cost formula would have to be nominal, acquired by multiplying equation (2) by the price index used to deflate nominal to real income. Regarding the choice of deflator, see Feenstra (1986).
} 
statistical index-number theory enables us to track $M_{t}$ exactly without estimating the unknown function, $u$.

In continuous time, the monetary aggregate, $M_{t}=u\left(\mathbf{m}_{t}^{*}\right)$, can be tracked exactly by the Divisia index,

which solves the differential equation

$$
\frac{d \log M_{t}}{d t}=\sum_{\mathrm{i}} s_{i t} \frac{d \log m_{i t}^{*}}{d t}
$$

for $M_{t}$, where

$$
s_{i t}=\frac{\pi_{i t} m_{i t}^{*}}{y_{t}}
$$

is the $i$ 'th asset's share in expenditure on the total portfolio's service flow. ${ }^{9}$ The dual user cost price aggregate $\Pi_{t}=\Pi\left(\pi_{t}\right)$, can be tracked exactly by the Divisia price index, which solves the differential equation

$$
\frac{d \log \Pi_{t}}{d t}=\sum_{\mathrm{i}} s_{i t} \frac{d \log \pi_{i t}}{d t} .
$$

The user cost dual satisfies Fisher's factor reversal in continuous time:

$$
\Pi_{t} M_{t}=\boldsymbol{\pi}_{t}^{\prime} \mathbf{m}_{t}
$$

As a formula for aggregating over quantities of perishable consumer goods, that index was first proposed by François Divisia (1925), with market prices and quantities of those goods used in equation (4). In continuous time, the Divisia index, under conventional neoclassical assumptions, is exact. In discrete time, the Törnqvist approximation is:

$$
\log M_{t}-\log M_{t-1}=\sum_{\mathrm{i}} \bar{s}_{i t}\left(\log m_{i t}^{*}-\log m_{i, t-1}^{*}\right),
$$

where

$$
\bar{s}_{i t}=\frac{1}{2}\left(s_{i t}+s_{i, t-1}\right) .
$$

In discrete time, we often call equation (7) simply the Divisia quantity index. ${ }^{10}$ After the quantity index is

\footnotetext{
${ }^{9}$ In equation (4), it is understood that the result is in continuous time, so the time subscripts are a short hand for functions of time. We use $t$ to be the time period in discrete time, but the instant of time in continuous time.

${ }^{10}$ Diewert (1976) defines a 'superlative index number' to be one that is exactly correct for a quadratic approximation to the aggregator function. The discretization (7) to the Divisia index is in the superlative class, since it is exact for the quadratic translog specification to an aggregator function. In practice, the resulting "monetary services index" often is computed as a 
computed from (7), the user cost aggregate most commonly is computed directly from equation (6).

\subsection{Risk Adjustment}

Extension of index number theory to the case of risk was introduced by Barnett, Liu and Jensen (1997), who derived the extended theory from Euler equations rather than from the perfect-certainty firstorder conditions used in the earlier index number-theory literature. Since that extension is based upon the consumption capital-asset-pricing model (CCAPM), the extension is subject to the 'equity premium puzzle' of smaller-than-necessary adjustment for risk. We believe that the under-correction produced by CCAPM results from its assumption of intertemporal blockwise strong separability of goods and services within preferences. Barnett and $\mathrm{Wu}(2005)$ have extended Barnett, Liu, and Jensen's result to the case of risk aversion with intertemporally non-separable tastes. ${ }^{11}$

\subsection{Dual Space}

User cost aggregates are duals to monetary quantity aggregates. Either implies the other uniquely. In addition, user-cost aggregates imply the corresponding interest-rate aggregates uniquely. The interestrate aggregate $r_{t}$ implied by the user-cost aggregate $\Pi_{t}$ is the solution for $r_{t}$ to the equation:

$$
\frac{R_{t}-r_{t}}{1+R_{t}}=\Pi_{t}
$$

Accordingly, any monetary policy that operates through the opportunity cost of money (that is, interest rates) has a dual policy operating through the monetary quantity aggregate, and vice versa. Aggregation theory implies no preference for either of the two dual policy procedures or for any other approach to policy, so long as the policy does not violate principles of aggregation theory. In their current state-space comparisons, Barnett, Chauvet, and Tierney model in quantity space rather than the user-costprice or interest-rate dual spaces. Regarding policy in the dual space, see Barnett (1987) and Belongia

Fisher ideal index, rather than as a Törnqvist index. Diewert (1978) has shown that the two indexes approximate each other very well.

${ }^{11}$ The Federal Reserve Bank of St. Louis Divisia database, which we use in this paper, is not risk corrected. In addition, it is not adjusted for differences in marginal taxation rates on different asset returns or for sweeps, and its clustering of components into groups was not based upon tests of weak separability, but rather on the Federal Reserve's official clustering. The St. Louis Federal Reserve Bank is in the process of revising its MSI database, perhaps to incorporate some of those adjustments. Regarding sweep adjustment, see Jones, Dutkowsky, and Elger (2005). At the present stage of this research, we felt it was best to use data available from the Federal Reserve for purposes of replicability and comparability with the official simple sum data. As a result, we did not modify the St. Louis Federal Reserve's MSI database or the Federal Reserve Board's simple sum data in any ways. This decision should not be interpreted to imply advocacy by us of the official choices. 
and Ireland (2006).

\subsection{Aggregation Error and Policy Slackness}

Figure 1 displays the magnitude of the aggregation error and policy slackness produced by the use of the simple sum monetary aggregates. Suppose there are two monetary assets over which the central bank aggregates. The quantity of each of the two component assets is $y_{1}$ and $y_{2}$. Suppose that the central bank reports, as data, that the value of the simple sum monetary aggregates is $M_{s s}$. The information content of that reported variable level is contained in the fact that the two components must be somewhere along the Figure 1 hyperplane, $y_{1}+y_{2}=M_{\mathrm{ss}}$, or more formally that the components are in the set $A$ :

$$
A=\left\{\left(y_{1}, y_{2}\right): y_{1}+y_{2}=M_{s s}\right\}
$$

But according to equation (3), the actual value of the service flow from those asset holdings is $u\left(y_{1}, y_{2}\right)$. Consequently the information content of the information set $A$ regarding the monetary service flow is that the service flow is in the set $E$ :

$$
E=\left\{u\left(y_{1}, y_{2}\right):\left(y_{1}, y_{2}\right) \in A\right\} .
$$

Note that $E$ is not a singleton. To see the magnitude of the slackness in that information, observe from Figure 1 that if the utility level (service flow) is $M_{\min }$, then the indifference curve does touch the hyperplane, $A$, at its lower right corner. Hence that indifference curve cannot rule out the $M_{s s}$ reported value of the simple sum monetary aggregate, although a lower level of utility is ruled out, since indifference curves at lower utility levels cannot touch the hyperplane, $A$.

Now consider the higher utility level of $M_{\max }$ and its associated indifference curve in Figure 1. Observe that that indifference curve also does have a point in common with the hyperplane, $A$, at the tangency. But higher levels of utility are ruled out, since their indifference curves cannot touch the hyperplane, $A$. Hence the information about the monetary service flow, provided by the reported value of the simple sum aggregate, $M_{s s}$, is the interval

$$
E=\left[M_{\min }, M_{\max }\right] .
$$

The supply side aggregation is analogous, but the lines of constant supplied service flow for financial firms are production possibility surfaces, not indifference surfaces, as shown by Barnett (1987). 


\section{The History of Thought on Monetary Aggregation}

The fields of aggregation and index number theory have a long history. The first book to put together the properties of all of the available index numbers in a systematic manner was the famous Irving Fisher (1922). He made it clear in that book that the simple sum and arithmetic average indexes are the worst known indexes. On p. 29 of that book he wrote:

"The simple arithmetic average is put first merely because it naturally comes first to the reader's mind, being the most common form of average. In fields other than index numbers it is often the best form of average to use. But we shall see that the simple arithmetic average produces one of the very worst of index numbers, and if this book has no other effect than to lead to the total abandonment of the simple arithmetic type if index number, it will have served a useful purpose.”

On p. 361 Fisher wrote:

"The simple arithmetic should not be used under any circumstances, being always biased and usually freakish as well. Nor should the simple aggregative ever be used; in fact this is even less reliable."

The simple sum monetary aggregates published by the Federal Reserve are produced from the "simple aggregative" quantity index. ${ }^{12}$ Indeed data-producing agencies and data-producing newspapers switched to reputable index numbers, following the appearance of Fisher's book. But there was one exception: the world's central banks, which produced their monetary aggregates as simple sums. While the implicit assumption of perfect substitutability in identical ratios might have made sense during the first half of the $20^{\text {th }}$ century, that assumption became unreasonable, as interest-bearing substitutes for currency were introduced by financial intermediaries, such as interest bearing checking and saving accounts.

Nevertheless, the nature of the problem was understood by Friedman and Schwartz (1970,

\footnotetext{
${ }^{12}$ While Fisher's primary concern was price index numbers, any price index formula has an analogous quantity index number acquired by interchanging prices and quantities. Since the formulas are intended to track an increasing, linearly homogeneous, concave aggregator function in either case, the properties of the formula are the same, whether used as a price or a quantity index number.
} 
151-152), who wrote the following:

"The [simple summation] procedure is a very special case of the more general approach. In brief, the general approach consists of regarding each asset as a joint product having different degrees of 'moneyness,' and defining the quantity of money as the weighted sum of the aggregated value of all assets.... We conjecture that this approach deserves and will get much more attention than it has so far received."

More recently, subsequent to Barnett's derivation of the Divisia monetary aggregates, Lucas (2000, p. 270) wrote:

"I share the widely held opinion that M1 is too narrow an aggregate for this period [the 1990s], and I think that the Divisia approach offers much the best prospects for resolving this difficulty."

\section{The 1960s and 1970s}

Having surveyed the theory and some of the relevant historical background, we now provide some key results. We organize them chronologically, to make the evolution of views clear. We first provide results for the 1960s and 1970s. The formal econometric source of the graphical results in this section, along with further modeling and inference details, can be found in Barnett, Offenbacher, and Spindt (1984) and Barnett (1982).

Demand and supply of money functions were fundamental to macroeconomics and to central bank policy until the 1970s, when questions began to arise about the stability of those functions. It was common for general equilibrium models to determine real values and relative prices, and for the demand and supply for money to determine the price level and thereby nominal values. But it was believed that something went wrong in the 1970s. In Figure 2, observe the behavior of the velocity of M3 and M3+ (later called L), which were the two broad aggregates often emphasized in that literature. For the demand for money function to have the correct sign for its interest elasticity (better modeled as user-cost price elasticity), velocity should move in the same direction as nominal interest rates.

Figure 3 provides an interest rate during the same time period. Note that while nominal interest rates were increasing during the growing inflation of that decade, the velocity of the simple sum monetary aggregates in Figure 2 were decreasing. While the source of concern is evident, note that the problem did 
not exist, when the data were produced from index number theory.

Much of the concern in the 1970s was focused on 1974, when it was believed that there was a sharp structural shift in money markets. Figure 4 displays a source of that concern. As is evident from this figure - which plots velocity against a bond rate, rather than against time - there appears to be a dramatic shift downwards in that velocity function in 1974. But observe that this result was acquired using simple sum M3. Figure 5 displays the same cross plot of velocity against an interest rate, but with M3 computed as its Divisia index. Observe that velocity no longer is constant, either before or after 1974. But there is no structural shift.

There were analogous concerns about the supply side of money markets. The reason is evident from Figure 6, which plots the base multiplier against a bond rate's deviation from trend. The base multiplier is the ratio of a monetary aggregate to the monetary base. In this case, the monetary aggregate is again simple sum M3. Observe the dramatic structural shift. Prior to 1974, the function was a parabola. After 1974 the function is an intersecting straight line. But again this puzzle was produced by the simple-sum monetary aggregate. In Figure 7, the same plot is provided, but with the monetary aggregate changed to Divisia M2. The structural shift is gone.

The econometric methods of investigating these concerns at the time were commonly based on the use of the Goldfeld (1973) demand for money function, which was the standard specification used by the Federal Reserve System. The equation was a linear regression of a monetary aggregate on national income, a regulated interest rate, and an unregulated interest rate. It was widely believed that the function had become unstable in the 1970s.

Swamy and Tinsley (1980), at the Federal Reserve Board in Washington, DC, had produced a stochastic coefficients approach to estimating a linear equation. The result was an estimated stochastic process for each coefficient. The approach permitted testing the null hypothesis that all of the stochastic processes are constant. Swamy estimated the processes for the model's three coefficients at the Federal Reserve Board with quarterly data from 1959:2 - 1980:4, and the econometric results were published by Barnett, Offenbacher, and Spindt (1984). The realizations of the three coefficient processes are displayed in Figures 8, 9, and 10 below. The solid line is the process's realization, when money is measured by 
simple sum M2. The dotted line is the realization, when the monetary aggregate is measured by the Divisia index. The instability of the coefficient is very clear, when the monetary aggregate is simple sum; but the processes look like noise around a constant, when the monetary aggregate is Divisia. The statistical test could not reject constancy (i.e., stability of the demand for money function), when Divisia was used. But stability was rejected, when the monetary aggregate was simple sum.

\section{The Monetarist Experiment: November 1979 - November 1982}

Following the inflationary 1970s, Paul Volcker, as Chairman of the Federal Reserve Board, decided to bring inflation under control by decreasing the rate of growth of the money supply, with the instrument of policy being changed from the federal funds rate to nonborrowed reserves. The period, November 1979 - November 1982, during which that policy was applied, was called the "Monetarist Experiment." The policy succeeded in ending the escalating inflation of the 1970 s, but was followed by an unintended recession. The Federal Reserve had decided that the existence of widespread 3-year negotiated wage contracts precluded a sudden decrease in the money supply growth rate to the intended long run growth rate. The decision was to decrease from the high double-digit growth rates to about $10 \%$ per year and then gradually decrease towards the intended long run growth rate to avoid inducing a recession.

Figure 11 and Table 1 reveal the cause of the unintended recession. As is displayed in Figure 11 for the M3 levels of aggregation, the rate of growth of the Divisia monetary aggregate was substantially less than the rate of growth of the official simple-sum-aggregate intermediate targets. As Table 1 summarizes, the simple sum aggregate growth rates were at the intended levels, but the Divisia growth rates were half as large, producing a negative shock of substantially greater magnitude than intended. For computational details, see Barnett (1984). A recession followed.

\section{End of the Monetarist Experiment: 1983 - 1984}

Following the end of the Monetarist Experiment and the unintended recession that followed, Milton Friedman became very vocal with his prediction that there had just been a huge surge in the growth rate of the money supply, and that surge would work its way through the economy and produce a new 
inflation. He further predicted that there would subsequently be an overreaction by the Federal Reserve, plunging the economy back down into a recession. He published this view repeatedly in the media in various magazines and newspapers, with the most visible being his Newsweek article, "A Case of Bad Good News," which appeared on p. 84 on September 26, 1983. We have excerpted some of the sentences from that Newsweek article below:

“The monetary explosion from July 1982 to July 1983 leaves no satisfactory way out of our present situation. The Fed's stepping on the brakes will appear to have no immediate effect. Rapid recovery will continue under the impetus of earlier monetary growth. With its historical shortsightedness, the Fed will be tempted to step still harder on the brake - just as the failure of rapid monetary growth in late 1982 to generate immediate recovery led it to keep its collective foot on the accelerator much too long. The result is bound to be renewed stagflation - recession accompanied by rising inflation and high interest rates... The only real uncertainty is when the recession will begin."

But on exactly the same day, September 26, 1983, William Barnett published a very different view in his article, "What Explosion?" on p. 196 of Forbes magazine. The following is an excerpt of some of the sentences from that article:

"People have been panicking unnecessarily about money supply growth this year. The new bank money funds and the super NOW accounts have been sucking in money that was formerly held in other forms, and other types of asset shuffling also have occurred. But the Divisia aggregates are rising at a rate not much different from last year's... the 'apparent explosion' can be viewed as a statistical blip."

Milton Friedman would not have taken such a strong position without reason. You can see the reason from Figure 12. The percentage growth rates in that figure are divided by 10 , so should be multiplied by 10 to acquire the actual growth rates. Notice the large spike in growth rate, which rises to near $30 \%$ per year. But that solid line is produced from simple sum M2, which was greatly overweighting the sudden new availability of super-NOW accounts and money market deposit accounts. There was no spike in the Divisia monetary aggregate, represented by the dashed line.

If the huge surge in the money supply had happened, then inflation would surely have followed, unless money is extremely non-neutral even in the short run --- a view held by very few economists. But 
there was no inflationary surge and no subsequent recession.

\section{The Rise of Risk Adjustment Concerns: 1984 - 1993}

The exact monetary quantity aggregator function, $m_{t}=\mathrm{u}\left(\mathbf{m}_{\mathrm{t}}\right)$, can be tracked very accurately by the Divisia monetary aggregate, $m_{t}{ }^{d}$, since its tracking ability is known under perfect certainty. However, when nominal interest rates are uncertain, the Divisia monetary aggregate's tracking ability is somewhat compromised. That compromise is eliminated by using the extended Divisia monetary aggregate under risk derived by Barnett, Liu, and Jensen (1997). Let $m_{t}{ }^{G}$ denote the extended "generalized" Divisia monetary aggregate. The only difference between $\mathrm{m}_{t}^{\mathrm{G}}$ and $\mathrm{m}_{t}{ }^{\mathrm{d}}$ is the risk-adjusted user cost formula used to compute the prices in the generalized Divisia index formula.

Let $\pi_{\mathrm{it}}{ }^{\mathrm{G}}$ denote the generalized user cost of monetary asset $i$. Under CCAPM (consumptions capital asset pricing) assumptions, Barnett, Liu, and Jensen (1997) prove that

$$
\pi_{i t}^{G}=\pi_{i t}^{e}+\varphi_{i t}
$$

where

$$
\pi_{i t}^{e}=\frac{E_{t}\left(R_{t}-R_{i t}\right)}{E_{t}\left(1+R_{t}\right)}
$$

and

$$
\varphi_{i t}=\frac{E_{t}\left(1+R_{i t}\right)}{E_{t}\left(1+R_{t}\right)} \frac{\operatorname{Cov}\left(R_{t}, \frac{\partial T}{\partial C_{t+1}}\right)}{\frac{\partial T}{\partial C_{T}}}-\frac{\operatorname{Cov}\left(R_{i t}, \frac{\partial T}{\partial C_{t+1}}\right)}{\frac{\partial T}{\partial C_{t}}},
$$

where

$$
T=E_{t} \sum_{t=0}^{\infty} \beta^{t} F\left(c_{t}, m_{t}^{G}\right) .
$$

Barnett, Liu, and Jensen (1997) show that the values of $\varphi_{i t}$ determine the risk premia in interest rates. Note that $\pi_{i t}{ }^{G}$ reduces to equation (2) under perfect certainty. 
Using that extension, Barnett and Xu (1998) demonstrated that velocity will change, if the variance of an interest rate stochastic process changes. Hence the variation in the variance of an interest rate $\mathrm{ARCH}$ or GARCH stochastic process cannot be ignored in modelling monetary velocity. By calibrating a stochastic dynamic general equilibrium model, Barnett and Xu (1998) showed that the usual computation of the velocity function will be unstable, when interest rates exhibit stochastic volatility. But when the CCAPM adjusted variables above are used, so that the variation in variance is not ignored, velocity is stabilized.

Figure 13 displays the simulated slope coefficient for the velocity function, treated as a function of the exact interest rate aggregate, but without risk adjustment. All functions in the model are stable, by construction. Series 1 was produced with the least stochastic volatility in the interest rate stochastic process, series 2 with greater variation in variance, and series 3 with even more stochastic volatility. Note that the velocity function slope appears to be increasingly unstable, as stochastic volatility increases. By the model's construction, the slope of the velocity function is constant, if the CCAPM risk adjustment is used. In addition, with real economic data, Barnett and $\mathrm{Xu}$ (1998) showed that the evidence of velocity instability is partially explained by overlooking the variation in the variance of interest rates over time.

Subsequently Barnett and Wu (2005) found that the explanatory power of the risk adjustment increases, if the assumption of intertemporal separability of the intertemporal utility function, $\mathrm{T}$, is weakened. The reason is the same as a source of the well known equity premium puzzle, by which CCAPM under intertemporal separability under-corrects for risk.

The Divisia index tracks the aggregator function, which measures service flow. But for some purposes, the economic capital stock, computed from the discounted expected future service flow, is relevant, especially when investigating wealth effects of policy. The economic stock of money (ESM), as defined by Barnett (2000) under perfect foresight, follows 
immediately from the manner in which monetary assets are found to enter the derived wealth constraint, (2.3). As a result, the formula for the economic stock of money under perfect foresight is

$$
V_{t}=\sum_{s=t}^{\infty} \sum_{i=1}^{n}\left[\frac{p_{s}^{*}}{\rho_{s}}-\frac{p_{s}^{*}\left(1+r_{i s}\right)}{\rho_{s+1}}\right] m_{i s},
$$

where the true cost of living index on consumer goods is $p_{s}^{*}=p_{s}^{*}\left(\mathbf{p}_{\mathrm{s}}\right)$, with the vector of consumer goods prices being $\mathbf{p}_{\mathrm{s}}$, and where the discount rate for period $s$ is

$$
\rho_{s}=\left\{\begin{array}{ccc}
1 & \text { for } & s=t \\
\prod_{u=t}^{s-1}\left(1+R_{u}\right) & \text { for } & s>t
\end{array} .\right.
$$

The CCAPM extension of the economic capital stock formula to risk is available from Barnett, Chae, and Keating (2006).

During the late 1980s and early 1990s, there was increasing concern about substitution of monetary assets within the monetary aggregates (especially money market mutual funds) with stock and bond mutual funds, which are not within the monetary aggregates. The Federal Reserve Board staff considered the possibility of incorporating stock and bond mutual funds into the monetary aggregates. Barnett and Zhou (1994a) used the formulas above to investigate the problem. They produced the figures that we reproduce below as Figures 14 and 15. The dotted line is the simple sum monetary aggregate, which Barnett (2000) proved is equal to the sum of economic capital stock of money, $V_{t}$, and the discounted expected investment return from the components.

Computation of $V_{t}$ requires modeling expectations. In that early paper, Barnett and Zhou (1994a) used martingale expectations rather than the more recent approach of Barnett, Chae, and Keating, using VAR forecasting. When martingale expectations are used, the index is called CE. Since the economic capital stock of money, $V_{t}$, is what is relevant to macroeconomic theory, we should concentrate on the solid lines in those figures. Note that Figure 15 displays nearly 
parallel time paths, so that the growth rate is about the same in either. That figure is for M2+, which was the Federal Reserve Board staff's proposed extended aggregate, adding stock and bond mutual funds to M2. But note that in Figure 14, the gap between the two graphs is decreasing, producing a slower rate of growth for the simple sum aggregate than for the economic stock of money.

The gap between the two lines is the amount motivated by investment yield. Clearly those gaps had been growing. But it is precisely that gap which does not measure monetary services. By adding the value of stock and bond mutual funds into Figure 14 to get Figure 15, the growth rate error of the simple sum aggregate is offset by adding in an increasing amount of assets providing nonmonetary services. Rather than trying to stabilize the error gap by adding in more and more nonmonetary services, the correct solution would be to remove the entire error gap by using the solid line in Figure 14, which measures the actual economic capital stock of money.

\section{The Y2K Computer Bug: 1999-2000}

The next major concern about monetary aggregates and monetary policy arose at the end of 1999. In particular, the financial press became highly critical of the Federal Reserve for what was perceived by those commentators to be a large, inflationary surge in the monetary base. The reason is clear from Figure 16. But in fact there was no valid reason for concern, since the cause was again a problem with the data.

The monetary base is the sum of currency plus bank reserves. Currency is dollar for dollar pure money, while reserves back deposits in an amount that is a multiple of the reserves. Hence as a measure of monetary services, the monetary base is severely defective, even though it is a correct measure of "outside money." At the end of 1999, there was the so-called Y2K computer bug, which was expected to cause temporary problems with computers throughout the world, including at banks. Consequently many depositors withdrew funds from their checking accounts and moved them into cash. While the decrease in deposits thereby produced an equal increase in 
currency demand, the decrease in deposits produced a smaller decline in reserves, because of the multiplier from reserves to deposits. The result was a surge in the monetary base, even though the cause was a temporary dollar-for-dollar transfer of funds from demand deposits to cash, having little effect on economic liquidity. Once the computer bug was resolved, people put the withdrawn cash back into deposits, as is seen from Figure 17.

\section{The Supply Side}

While much of the concern in this literature has been about the demand for money, there is a parallel literature about the supply of money by financial intermediaries. Regarding the aggregation theoretic approach, see Barnett and Hahm (1994) and Barnett and Zhou (1994b). It should be observed that the demand-side Divisia monetary aggregate, measuring perceived service flows received by financial asset holders, can be slightly different from the supply-side Divisia monetary aggregate, measuring service flows produced by financial intermediaries. The reason is the regulatory wedge resulting from non-interest-bearing required reserves. That wedge produces a difference between demand side and supply-side user-cost prices and thereby can produce a small difference between the demand side and supply side Divisia aggregates.

When there are no required reserves and hence no regulatory wedge, the general equilibrium looks like Figure 18, with the usual separating hyperplane determining the user cost prices, which are the same on both sides of the market. The production possibility surface between deposit types 1 and 2 is for a financial intermediary, while the indifference curve is for a depositor allocating funds over the two asset types. In equilibrium, the quantity of asset $i$ demanded, $\mathrm{m}_{\mathrm{it}}$, is equal to the quantity supplied, $\mu_{\mathrm{it}}$, and the slope of the separating hyperplane determines the relative user costs on the demand side, $\pi_{\mathrm{it}}$, which are equal to those on the supply side, $\gamma_{\mathrm{it}}$.

That diagram assumes that the same user-cost prices are seen on both sides of the market. 
But when noninterest-bearing required reserves exist, the foregone investment return to banks is an implicit tax on banks and produces a regulatory wedge between the demand and supply side. It was shown by Barnett (1987) that under those circumstances, the user cost of supplied financial services by banks is not equal to the demand price, (2), but rather is

$$
\gamma_{i t}=\frac{\left(1-k_{i t}\right) R_{t}-r_{i t}}{1+R_{t}}
$$

where $k_{i t}$ is the required reserve ratio for account type $i, \mathrm{r}_{i t}$ again is the interest rate paid on deposit type $i$, and now the bank's benchmark rate, $\mathrm{R}_{t}$, is its loan rate. Note that this supply-side user cost is equal to the demand-side formula, (2), when $k_{i t}=0$, if the depositor's benchmark rate is equal to the bank's loan rate, as in classical macroeconomics, in which there is one pure investment rate of return. ${ }^{13}$

The resulting general equilibrium diagram, with the regulatory wedge, is displayed in Figure 19. Notice that one tangency determines the supply-side prices, while the other tangency produces the demand-side prices, with the angle between the two straight lines being the "regulatory wedge." Observe that the demand equals the supply for each of the two component assets.

Although the component demands and supplies are equal to each other, the failure of tangency between the production possibility curve and the indifference curve can result in a wedge between the growth rates of aggregate demand and supply services, as reflected in the fact that the user cost prices in the Divisia index are not the same in the demand and the supply side aggregates. To determine whether this wedge might provide a reason to compute and track the Divisia monetary supply aggregate as well as the more common demand-side Divisia monetary aggregate, Barnett, Hinich, and Weber (1986) conducted a detailed spectral analysis in the frequency domain. Figure 20 displays the squared coherence between the demand and supply side Divisia

\footnotetext{
${ }^{13}$ An excellent source on the supply side is Hancock (1985a,1985b,1991), who independently acquired many of the same results described in this section, but using a different procedure for determining inputs and outputs in production. Our view is that the distinction should be based upon value added in production, rather than upon the ex-post realization of the user cost price.
} 
monetary aggregates, where coherence measures correlation as a function of frequency. The figure provides those plots at three levels of aggregation. Note that the correlation usually exceeds $95 \%$ for all three levels of aggregation at all frequencies, but the coherence begins to decline at very high frequencies (i.e., very short cycle periods in months). Hence the difference between the demand and supply side monetary aggregates is relevant only in modelling very short run phenomena.

To put this into context, we displays plots in the time domain for simple-sum M3, the supplyside M3 Divisia index (SDM3), and the demand-side M3 Divisia index (DDM3) over the same time period used in producing the frequency domain comparisons. See Figure 21 for those plots. Notice that it takes over a decade for the difference between the demand side and supply side Divisia index to get wider than a pencil point, but the divergence between simple sum and either of the two Divisia aggregates begins immediately and is cumulative. In short, the error in using the simple-sum monetary aggregates is overwhelmingly greater than the usually entirely negligible difference between the demand and supply side Divisia monetary aggregates. Furthermore, in recent years reserve requirements have been low and largely offset by sweeps. In addition, the Federal Reserve recently began paying interest on required reserves, although not necessarily at bank's full loan rate. The difference between the demand and supply side Divisia monetary aggregates now is much smaller than during the time period displayed in Figures 20 and 21.

\section{The Great Moderation}

The most recent research on the comparison of microeconomic aggregated-based Divisia and the simple sum monetary aggregates is Barnett, Chauvet, and Tierney (2009). The paper proposes a latent factor Markov switching approach that separates out common dynamics in monetary aggregates from their idiosyncratic movements. The dynamic factor measures the common cyclical movements underlying the monetary aggregate indices. The idiosyncratic term 
captures movements peculiar to each index. The approach is used to provide pairwise comparisons of Divisia versus simple-sum monetary aggregates quarterly from 1960:2 to 2005:4. In that paper, they introduced the connection between the state-space time-series approach to assessing measurement error and the aggregation theoretic concept, with emphasis upon the relevancy to monetary aggregation and monetary policy.

\subsection{The Model}

Let $\mathbf{Y}_{\mathrm{t}}$ be the $n \times 1$ vector of monetary indexes, where $n$ is the number of monetary indexes in the model:

$$
\Delta \mathbf{Y}_{\mathrm{t}}=\lambda \Delta F_{t}+\gamma \tau_{\mathrm{t}}+\mathbf{v}_{\mathrm{t}}
$$

where $\Delta=1-\mathrm{L}$ and $\mathrm{L}$ is the lag operator. Changes in the monetary aggregates, $\Delta \mathbf{Y}_{\mathrm{t}}$, are modeled as a function of a scalar unobservable factor that summarizes their commonalities, $\Delta F_{\mathrm{t}}$; an idiosyncratic component $n \times 1$ vector, which captures the movements peculiar to each index, $\mathbf{v}_{\mathrm{t}}$; and a scalar potential time trend $\tau_{\mathrm{t}}$. The factor loadings, $\lambda$, measure the sensitivity of the series to the dynamic factor, $\Delta F_{\mathrm{t}}$. Both the dynamic factor and the idiosyncratic terms follow autoregressive processes:

$$
\begin{array}{ll}
\Delta F_{\mathrm{t}}=\alpha_{S_{t}}+\phi(\mathrm{L}) \Delta F_{\mathrm{t}-1}+\eta_{\mathrm{t}} & \eta_{\mathrm{t}} \sim \mathrm{N}\left(0, \sigma^{2}\right), \\
\mathbf{v}_{\mathrm{t}}=\boldsymbol{\Gamma}_{S_{t}^{h}}+\mathbf{d}(\mathrm{L}) \mathbf{v}_{\mathrm{t}-1}+\boldsymbol{\varepsilon}_{\mathrm{t},} & \boldsymbol{\varepsilon}_{\mathrm{t}} \sim \text { i.i.d. } \mathrm{N}(0, \Sigma),
\end{array}
$$

where $\eta_{\mathrm{t}}$ is the common shock to the latent dynamic factor, and $\varepsilon_{\mathrm{t}}$ are the measurement errors. In order to capture potential nonlinearities across different monetary regimes, the intercept of the monetary factor switches regimes according to a Markov variable, $S_{t}$, where $\alpha_{S_{t}}=\alpha_{0}+\alpha_{1} S_{t}^{\alpha}$, and $S_{t}^{\alpha}=0,1$. That is, monetary indexes can either be in an expansionary regime, where the mean growth rate of money is positive $\left(S_{t}^{\alpha}=1\right)$, or in a contractionary phase with a lower or negative mean growth rate $\left(S_{t}^{\alpha}=0\right)$.

We also assume that the idiosyncratic terms for each index follow distinct two-state 
Markov processes, by allowing their drift terms, $\Gamma_{S_{t}^{\text {h }}}$, to switch between regimes. For example, in the case of two monetary indexes, $n=2$, there will be two idiosyncratic terms, each one following an independent Markov process $S_{t}^{\beta}$ and $S_{t}^{\delta}$, where $S_{t}^{\beta}=0,1$ and $S_{t}^{\delta}=0,1$. Notice that we do not constraint the Markov variables $S_{t}^{\alpha}, S_{t}^{\beta}$, and $S_{t}^{\delta}$ to be dependent of each other, but allow them instead to move according to their own dynamics. In fact, there is no reason to expect that the idiosyncratic terms would move in a similar manner to each other or to the dynamic factor, since by construction they represent movements peculiar to each index not captured by the common factor.

The switches from one state to another is determined by the transition probabilities of the first-order two-state Markov processes, $p_{i j}^{k}=\mathrm{P}\left(S_{t}^{k}=j \mid S_{t-1}^{k}=i\right)$, where $\sum_{j=0}^{1} p_{i j}^{k}=1, i, j=0,1$, with $k=\alpha, \beta, \delta$ identifying the Markov processes for the dynamic factor and the two idiosyncratic terms, respectively.

The model separates out the common signal underlying the monetary aggregates from individual variations in each of the indexes. The dynamic factor captures simultaneous downturns and upturns in money growth indexes. On the other hand, if only one of the variables declines, e.g. M1, this would not characterize a general monetary contraction in the model and would be captured by the M1 idiosyncratic term. A general monetary contraction (expansion) will occur when all $n$ variables decrease (increase) at about the same time. That is, $\eta_{\mathrm{t}}$ and $\mathbf{v}_{\mathrm{t}}$ are assumed to be mutually independent at all leads and lags for all $n$ variables, and $\mathbf{d}(\mathrm{L})$ is diagonal. The dynamic factor is the outcome of averaging out the discrete states. Although the $n$ monetary indexes represent different measurements of money, the estimated dynamic factor is a nonlinear combination of them, representing broader movements in monetary aggregates in the U.S. On the other hand, once a contraction or expansion is clearly under way, the idiosyncratic term for a particular aggregate can be highly informative near a turning point.

Dynamic factor models with regime switching have been widely used to represent business 
cycles. The proposed model differs from the literature in its complexity, as it includes estimation of the parameters of three independent Markov processes.

The model is cast in state space form, where (11) and (12) are the measurement and transition equations, respectively:

$$
\begin{aligned}
& \Delta \mathbf{Y}_{\mathrm{t}}=\mathbf{Z} \boldsymbol{\xi}_{\mathrm{t}}+\mathbf{G} \tau_{\mathrm{t}} \\
& \boldsymbol{\xi}_{\mathrm{t}}=\boldsymbol{\mu}_{\xi_{s t}}+\mathbf{T} \boldsymbol{\xi}_{\mathrm{t}-1}+\mathbf{u}_{\mathrm{t}} .
\end{aligned}
$$

A particular state space representation for the estimated indicator using two variables is:

$$
\begin{aligned}
& \Delta \mathbf{Y}_{\mathrm{t}}=\left[\begin{array}{c}
\Delta Y_{1 t} \\
\Delta Y_{2 t}
\end{array}\right], \quad \mathbf{Z}=\left[\begin{array}{cccc}
\lambda_{1} & 1 & 0 & 0 \\
1 & 0 & 1 & 0
\end{array}\right], \quad \xi_{\mathrm{t}}=\left[\begin{array}{c}
\Delta F_{t} \\
v_{1 t} \\
v_{2 t} \\
F_{t-1}
\end{array}\right] \boldsymbol{\mu}_{\xi_{s t}}=\left[\begin{array}{c}
\alpha_{s t} \\
\beta_{s t} \\
\delta_{s t} \\
0
\end{array}\right], \\
& \mathbf{T}=\left[\begin{array}{cccc}
\phi_{1} & 0 & 0 & 0 \\
0 & d_{1} & 0 & 0 \\
0 & 0 & d_{2} & 0 \\
1 & 0 & 0 & 1
\end{array}\right], \quad \mathbf{G}=\left[\begin{array}{c}
\gamma_{1} \\
\gamma_{2}
\end{array}\right] \text { and } \quad \mathbf{u}_{\mathrm{t}}=\left[\begin{array}{c}
\eta_{t} \\
\varepsilon_{1 t} \\
\varepsilon_{2 t} \\
0
\end{array}\right] .
\end{aligned}
$$

The term $F_{\mathrm{t}-1}$ is included in the state vector to allow estimation of the dynamic factor in levels from the identity $\Delta F_{\mathrm{t}-1}=F_{\mathrm{t}-1}-F_{\mathrm{t}-2}$.

Barnett, Chauvet and Tierney (2009) estimate three models, one for each pair of the rate of growth of monetary indexes: simple sum M1 and Divisia M1, simple sum M2 and Divisia M2, and simple sum M3 and Divisia M3, where Divisia corresponds to the "monetary services index" (MSI) computed from the Divisia index by the St. Louis Federal Reserve Bank.

\subsection{Results}

There are some remarkable short run differences between simple sum and Divisia monetary aggregates, as shown in Barnett, Chauvet, and Tierney (2009). Figure 22 displays the idiosyncratic terms specific to the growth rates of Divisia M3 and simple sum M3, and NBER- 
dated recessions. ${ }^{14}$ Recall that the idiosyncratic terms indicate in which ways the two aggregates differ.

First, the idiosyncratic term for M3 is generally higher than the one for Divisia M3 before 1984, especially in the 1970s. However, after 1984 this pattern reverts, and M3 is generally lower than Divisia M3. This is also the case for the difference between the indices Divisia M3 and simple sum M3, also shown in Figure 22. That is, before 1984 the more precise measure of the growth rate of money supply (Divisia M3) was smaller than what was perceived (as measured by the official simple sum M3). On the other hand, during the Great Moderation the rate of growth of money supply as measured by Divisia was higher than perceived, as measured by simple sum. That is, monetary policy was more contractionary before 1984 and more expansive during the Great Moderation than shown by simple sum. This result, at the least, calls for a re-examination of the extensive literature that investigates tightness of monetary policy before and after 1984.

Second, the idiosyncratic terms differ substantially around recessions. Compare Divisia M3's idiosyncratic downward spikes in Figure 22 with simple sum M3's idiosyncratic behavior and then compare the relative predictive ability of the two extracted idiosyncratic terms with respect to NBER recessions. The Divisia M3 decreases a lot more before recessions (at the peak of inflation phases) and increase substantially more during recessions and recoveries (corresponding to low interest rate phases) than the simple sum aggregate M3, respectively. This is also observed in the difference between the two indices as depicted in Figure 22. Accordingly, the Divisia index displays a business cycle pattern more consistent with monetary policy. However, notice as well as that more contractionary policy before recessions than

\footnotetext{
14 This pattern is also observed between the simple sum M2 and Divisia M2 monetary aggregate. In particular, the major divergences between simple sum M3 and Divisia M3 growth coincide in time and amplitude with the differences between simple sum M2 and Divisia M2 growth. We will report here the results for M3. Details on the results for M1 and M2 can be found in Barnett, Chauvet, Tierney (2009).
} 
intended could have contributed for the onset of these phases of weak economic activity.

The most notable differences between Divisia M3 and simple sum M3 take place between 1978 and 1982, a period that includes the changes in the Fed operation procedures, a slowdown, and two recessions. As discussed in section 5, the Divisia index was substantially lower than simple sum M3, especially right before the 1980 and 1981 recessions. The only recession that was not preceded by a fall in the Divisia index was the 1990-1991 (the Divisia index decreased in 1989 but had a subsequent increase before the onset of this recession). Thus, with the exception of the 1990 recession, monetary policy has been more contractionary before recessions than intended. This is the case before or during the Great Moderation.

Figure 23 plots the idiosyncratic terms for Divisia and simple sum, but now against high interest rates phases. ${ }^{15}$ The differences between the Divisia M3 and the simple sum M3 are even more striking during these phases. Generally, at the beginning of high interest rate phases the idiosyncratic term for Divisia M3 starts to fall, and reaches its lowest values towards the end of these phases. At the trough, the idiosyncratic term for Divisia M3 starts to increase. ${ }^{16}$ This pattern is not observed in the idiosyncratic term for simple sum M3. That is, the dynamics of these Divisia indexes correspond more closely to the expected movements related to interest rates and inflation. Recall that the idiosyncratic terms show when the two series differ - that is, what they do not have in common.

In a speech at the Fourth ECB Central Banking Conference, Chairman Bernanke (2006) discussed some potential problems of the use of simple sum monetary aggregates for monetary policy. In particular, he mentions that between 1991 and 1992 simple sum M2 grew much more

\footnotetext{
15 Barnett, Chauvet and Tierney (2009) classify a high interest rate phase as one in which the Federal Funds rate increases persistently for two quarters, and lasts until it reaches a peak. Analogously, low interest rate phases start when the Fed Funds rate falls for two quarters, and lasts until it reaches a trough.

16 Note, however, that this relationship is not one-to-one. For general utility functions, the direction of the change in shares with a price change, or equivalently with an interest rate change, depends upon whether the own price elasticity of demand exceeds or is less than -1 . This is the case, for example, in the early and late 1960s.
} 
slowly than was predicted by models used by the Federal Reserve Board. In particular, the socalled $P^{*}$ model, which used simple sum M2 in the quantity theory of money and estimates of long-run potential output and velocity to predict long-run inflation trends even predicted deflation for these years. Figure 24 shows the differences between Divisia M2 and simple sum M2. The rate of growth of Divisia M2 was substantially higher than the rate of growth of simple sum M2 during this period.

\section{The 2008 Financial Crisis}

\subsection{Prior to July 2004}

We believe that the highly-leveraged investment, borrowing, and lending that led up to the current crisis were not "irrational" relative to the views that had widely arisen about the Great Moderation and the Greenspan Put. The problem was the information set which the expectations were conditioned. There is evidence that the monetary policy in recent decades may have been more expansionary than was realized by the Federal Reserve and thereby may have fed the bubbles. There is also evidence that policy may have been more contractionary than realized by the Federal Reserve at the start of the crisis. We wish to emphasize that the evidence is not unambiguous in these regards, largely as a result of unfortunate Federal Reserve data limitations. In addition to the problems emphasized in this paper, there also is the fact that the Federal Reserve reports demand deposits post-sweeps, thereby biasing downwards both M1, M2, and M3, with the bias in M1 being especially severe. However, since sweeps are excluded from both simple sum and Divisia aggregates, the difference between these two indices are not affected by this problem. ${ }^{17}$ In any case, we feel that it is worthwhile providing the evidence that we have.

There is a strain of thought that maintains that the current U.S. financial crisis was prompted by excessive money creation fueling the bubbles. The process started in early 2001, when money supply growth was increased substantially to minimize the economic recession that had started in March of that year. However, in contrast with previous recessions, money supply growth continued to be high for a few

\footnotetext{
${ }^{17}$ In order to evade reserve requirements, banks sweep demand deposits into money-market deposit savings accounts, but continue to service them as regular demand deposits. Thus, the method of aggregation is not the only problem. See, e.g., Jones, Dutkowsky, and Elger (2005).
} 
years after the recession's end in November 2001. In fact, money supply growth was high until mid 2004, after which it started decreasing slowly. The argument is that the monetary expansion during this first period led to both speculation and leveraging, especially regarding lending practices in the housing sector. This expansion is argued as having made it possible for marginal borrowers to obtain loans with lower collateral values. When money creation slowed, housing prices began to decline, leading many to own negative equity and inducing a wave of defaults and foreclosures.

If this were the case, it would be worthwhile to ask what would have motivated the policy that had this outcome. We see no reason to believe that the Federal Reserve would have as a goal to create 'excessive' money growth. Had they known that the amount of money circulating in the economy was excessive and could generate an asset bubble, monetary policy would have been reverted long before it did.

Figures 25a and 25b display the idiosyncratic term for simple sum M3 and Divisia M3, as well as the difference between the two monetary aggregates for the recent period, plotted against the NBER-dated recession and high interest rate phases, respectively. First, notice that, as in the case of the previous recessions, the idiosyncratic term for Divisia M3 before the 2001 recession falls substantially more than the idiosyncratic term for simple sum M3. This is also observed in the difference between the rate of growth of the two indices. As shown in the figure, the subsequent increase in money supply growth during the 2001 recession, as measured by Divisia M3, was substantially larger than as measured by simple sum M3. In addition, Divisia money supply growth continued to be much higher than simple sum money supply between 2001 and 2003. Thus, the actual money supply growth post-recession was even higher than what was intended. These differences between the two indexes confounded monetary policy by underestimating the real amount of money available in the economy, as measured by the Divisia index.

\subsection{Subsequent to July 2004.}

There may be some truth to the view that the recent bubble economy was accommodated by years of excessively expansionary monetary policy. Since all bubbles eventually burst, it is thereby argued that the current problems were unavoidable. Whether or not that view is correct, it is interesting to ask what 
broke the bubble, even if it eventually would have burst anyway. Comparison of the Divisia and simple sum monetary aggregates and inspection of Federal Reserve data provide relevant information.

The Federal Reserve had been increasing the target value for the federal funds rate since June 2004. As can be seen in Figure 25b, this corresponded to a decrease in the idiosyncratic terms for M3 and Divisia M3. However, Divisia M3 fell substantially more than the simple sum M3. The difference between the two indices increases substantially until the end of the sample in 2005:4. ${ }^{18}$ Thus, the official simple sum M3 masks, once again, a much more contractionary policy by the Federal Reserve than intended, as also occurred prior to most recessions in the last 50 years.

By conventional measures, the Federal Reserve has been easing its monetary policy stance by reducing its target value for the federal funds interest rate from 5.25 percent in September 2007 to its recent level of near zero percent in 2008 and 2009. Has the Fed thereby been engaging in actions that are stimulative to economic activity? Low interest rates do not necessarily an expansionary monetary policy make.

It is helpful to illustrate the problem with a different central bank activity: sterilized exchange rate intervention. When the Fed decides to intervene in foreign exchange markets, its foreign desk swaps dollar-denominated assets for assets denominated in a foreign currency. Left unchecked at this point, the reserves of the U.S. banking system (and the U.S. money supply) would change, as would the market value of the federal funds interest rate. To sterilize the foreign exchange transaction, the domestic desk of the Fed, in a subsequent operation, either buys or sells U.S. Treasuries in a magnitude sufficient to offset the impact of the foreign desk's activity and thereby keeps the U.S. money supply, the federal funds rate, and the reserves of the U.S. banking system unchanged. On net, two things are accomplished by these offsetting transactions by the Fed's foreign and domestic desks: creating the symbolic gesture of "doing something" about the dollar's value and exposing the U.S. taxpayer to potential losses, if subsequent changes in the exchange rate cause losses in the market value of the foreign assets now on the Fed's books.

\footnotetext{
18 We have no way of knowing the pattern of the broader aggregates, M3 and L, from 2006 on, since collection of both has been terminated by the Federal Reserve.
} 
Similarly, much recent Federal Reserve activity, including its role in bailouts, has been sterilized and has had little effect on bank reserves, while exposing the taxpayers to sub-standard asset risk. To illustrate the point, the Federal Reserve Figure 26 shows the total amount of reserves in the U.S. banking system over the past five years. Note that reserves - the raw material from which loans and spending are created - are lower in mid-2008 than in August of 2003! But changes in the funds rate are usually interpreted in the media as the product of Fed policy actions. According to that view, if the funds rate declines, it must be the result of an expansionary monetary policy action. Missing from this analysis is the other side of the reserves market: those who demand reserves have some ability to affect the price i.e., the federal funds rate - at which reserves trade. Those demanders are banks that see the demand for reserves rise and fall along with the demand for loans. When the demand for loans falls, the demand for reserves by banks declines. Hence, the federal funds rate can decline, because of declines in the demands for loans and reserves, without the Fed taking any policy action. While a decline in the funds rate is usually interpreted as "evidence" of an easy policy stance, the real signal in the market may be that the economy is weakening.

The Great Depression and the recent history of Japan's long stagnation reveal that low interest rates, per se, are ambiguous indicators of the relative ease of monetary policy. The missing ingredient is the flow of bank reserves, the ultimate source of credit from which all other lending ultimately grows. For better or for worse, intentional or unintentional, herein may be the pin that pricked the recent bubble.

Subsequent to the Fed's publication of the discouraging Figure 26 chart below, there has been an enormous surge of reserves injected into the banking system through the Fed's lender-of-last-resort function at its discount window; through the new credit facilities, such as the Primary Dealer Credit Facility and Term Auction Facility; and through the long overdue initiation of the Fed's payment of interest on reserves - an important new reform that provides an incentive for banks to increase their holdings of reserves. See Figure 27.

\section{The Most Recent Data}


Considering these most recent results along with the many others provided in this paper, and the relevant microeconomic aggregation theory, you might find it to be worthwhile to compare the most recent behavior of the Taylor rule, which does not use money at all. Figure 28 is reproduced from the St. Louis Federal Reserve Bank's publication, Monetary Trends. That figure displays the range of the target for the federal funds rate produced from the Taylor rule along with the actual interest rate over that time period, where the actual funds rate is the dark solid line. Notice that the actual interest rate was off target for more than three successive years. Perhaps we now have a new paradox: the appearance of instability of the Taylor rule.

As documented in this paper, monetary policy and monetary research have been plagued by bad monetary aggregates data, resulting from simple sum aggregation, which has been disreputable in aggregation and index number theorist for over a half century. In addition, we have shown that the puzzles that have arisen since the early 1970s were produced by simple sum aggregation and would be resolved, if reputable index number formulas were used. With so much history and evidence and so much research documenting the data problems, it might be assumed that central banks would now be taking much care to provide high quality data that is consistent with economic theory.

But look at Figure 29, which was downloaded from the St. Louis Federal Reserve Bank web site and is produced from official Federal Reserve Board data. Recall that during Volcker's "Monetarist Experiment" period, the instrument of policy was nonborrowed reserves. Figure 29, displays official recent data on nonborrowed reserves from the Federal Reserve Board.

Total reserves are the sum of borrowed reserves and nonborrowed reserves. Nonborrowed reserves are those reserves that were not borrowed, while borrowed reserves are those reserves that were borrowed. Clearly everything included in borrowed reserves must be reserves, and everything contained in nonborrowed reserves must be reserves. Hence it is impossible for either borrowed reserves or nonborrowed reserves to exceed total reserves. A negative value for either borrowed reserves or nonborrowed reserves would be an oxymoron.

Observe that nonborrowed reserves recently have crashed to about minus 50 billion dollars. The Federal Reserve's explanation is that they are including the new auction borrowing from the Federal - 35 - 
Reserve in nonborrowed reserves, even though the new auction facility borrowing need not be held as reserves. Hence according to this "data," the instrument of monetary policy during Volcker's Monetarist Experiment period now has been driven to a very negative value, which contradicts the definition of "nonborrowed reserves."19

Since the Bank of England is the only central bank in the world that publishes Divisia money officially, it is especially interesting to look at UK data. ${ }^{20}$ As the current recession developed, the Bank of England adopted a policy of "quantity easing" focusing on expanding the supply of monetary services, rather than interest rates, which already were at very low levels. Following that change in policy, there was little evidence of positive consequences. While this puzzled many who were following the Bank of England's simple sum monetary aggregates, Figure 30 displays both simple sum M4 and Divisia M4, both from the official Bank of England source. Clearly Divisia M4 reflects a tightening of policy, rather than the intended loosening, implied by simple sum M4. For further details of this phenomenon, see Rayton and Pavlyk (2010).

\section{Conclusion}

We have shown that most of the puzzles and paradoxes that have evolved in the monetary economics literature were produced by the simple-sum monetary aggregates, provided officially by most central banks, and are resolved by use of aggregation-theoretic monetary aggregates. We argue that official central-bank data throughout the world have not significantly improved, despite the existence of better data internal to some of those central banks for their own use. We document the fact that the profession, financial firms, borrowers, lenders, and central banks have repeatedly been misled by defective central-bank monetary data over the past half century.

Many commonly held views need to be rethought, since many such views were based upon

\footnotetext{
19 See Barnett (2009).

20 The US and ECB Divisia data are not supplied in a formally official manner. The St. Louis Federal Reserve Bank computes and supplies Divisia monetary aggregate data for the US, but the Federal Reserve Board in Washington, DC does not. The European Central Bank's (ECB) Governing Council is provided quarterly projections on economic and financial variables by the ECB's staff, along with information based upon the Divisia monetary aggregates in accordance with Barnett (2007). Since that ECB staff information is used to inform the Council on a confidential basis, the data are not provided to the public.
} 
atheoretical data. For example, the views on the Great Moderation need to be reconsidered, at least relative to the current crisis and the role of monetary policy. We find no reason to believe that the moderation in the business cycle during the past two decades had any appreciable connection with improved monetary policy, and in fact we find no reason to believe that there have been significant improvements in monetary policy over that time period. In particular, we believe that the increased risktaking that produced the recent financial crisis resulted from a misperception of cyclical systemic risk. The misperception was caused by rational expectations conditioned upon a faulty information set.

We do not take a position on what produced the Great Moderation, only on what did not. We are not comfortable with the widespread view that the source of the crisis is the irrational "greed" of the victims of the misperceptions, and we are not aware of a definition of the word "greed" in the field of economics. We similarly do not believe that the policy of the Federal Reserve was intentionally too expansionary during the evolution of the bubbles that preceded the current crisis or intentionally excessively contractionary as the bubbles burst. But we do find evidence supporting the view that the misperceptions and poor decisions in the private and public sectors of the economy were connected with defective data that are inconsistent with modern aggregation and index number theory and could have produced unrealistically excessive confidence in the capabilities of the Federal Reserve, as in Wall Street's confidence in "The Greenspan Put." ${ }^{, 1}$ In addition, we show that the misperceptions were connected with excessive liquidity that fed the bubble, and the crisis was connected with a more contractionary policy than intended. The recent economic consequences can be understood in that context.

\section{References}

Barnett, W.A., 1978, The User Cost of Money. Economics Letter 1, 145-149. Reprinted in W.A. Barnett and A. Serletis, (Eds.), 2000, The Theory of Monetary Aggregation, North Holland, Amsterdam, ch. 1, pp. 610.

21 Also see Chari, Christiano, and Kehoe (2008). 
Barnett, W.A., 1980, Economic Monetary Aggregates: An Application of Aggregation and Index Number Theory. Journal of Econometrics 14, 11-48. Reprinted in W.A. Barnett and A. Serletis, (Eds.), 2000, The Theory of Monetary Aggregation, North Holland, Amsterdam, ch. 1, pp. 6-10.

Barnett, W.A., 1982, The Optimal level of Monetary Aggregation. Journal of Money, Credit, and Banking 14, 687-710. Reprinted in W.A. Barnett and A. Serletis, (Eds.), 2000, The Theory of Monetary Aggregation, North Holland, Amsterdam, ch. 7, pp. 125-149.

Barnett, W.A., 1983, Understanding the New Divisia Monetary Aggregate. Review of Public Data Use 11, 349-355. Reprinted in W.A. Barnett and A. Serletis, (Eds.), 2000, The Theory of Monetary Aggregation, North Holland, Amsterdam, ch. 4, pp. 100-108.

Barnett, W.A., 1984, Recent Monetary Policy and the Divisia Monetary Aggregates. American Statistician 38, 162-172. Reprinted in W.A. Barnett and A. Serletis, (Eds.), 2000, The Theory of Monetary Aggregation, North Holland, Amsterdam, ch. 23, pp. 563-576.

Barnett, W.A., 1987, The Microeconomic Theory of Monetary Aggregation, in W.A. Barnett and Kenneth Singleton, (Eds.), New Approaches to Monetary Economics, Cambridge U. Press. Reprinted in W.A. Barnett and A. Serletis, (Eds.), 2000, The Theory of Monetary Aggregation, North Holland, Amsterdam, ch. 3, pp. 49-99.

Barnett, W.A., 1997, Which Road Leads to Stable Money Demand? The Economic Journal 107, 1171-1185. Reprinted in W.A. Barnett and A. Serletis, (Eds.), 2000, The Theory of Monetary Aggregation, North Holland, Amsterdam, ch. 24, pp. 577-592.

Barnett, W.A., 2000, A Reply to Julio J. Rotemberg. In: Belongia, M.T. (ed) Monetary policy on the 75th Anniversary of the Federal Reserve System. Boston: Kluwer Academic, 232-244 (1991). Reprinted in: Barnett, W.A., A. Serletis, (Eds.) The Theory of Monetary Aggregation. Amsterdam: North Holland, chapter 14, pp. 296-30.

Barnett, W.A., 2007, Multilateral Aggregation-Theoretic Monetary Aggregation over Heterogeneous Countries. Journal of Econometrics 136, 2, 457-482.

Barnett, W. A., 2009, Who's Looking at the Fed's Books? , New York Times, October 22, 2009, p. A35. 
Barnett, W. A, 2011, Getting It Wrong: How Faulty Monetary Statistics Undermine the Fed, MIT Press, Cambridge, MA, forthcoming.

Barnett, W. A. and M. Chauvet, 2010, Financial Aggregation and Index Number Theory: A Survey, World Scientific, Singapore, forthcoming.

Barnett, W.A. and J.H. Hahm, 1994, Financial Firm Production of Monetary Services: A Generalized Symmetric Barnett Variable Profit Function Approach. Journal of Business and Economic Statistics 12, 3346. Reprinted in W.A. Barnett and J. Binner, (Eds.), 2004, Functional Structure and Approximation in Econometrics, North Holland, Amsterdam, ch. 15, pp. 351-380.

Barnett, W.A. and P. Peretti, 2008, A Necessary and Sufficient Stochastic Semi-Nonparametric Test for Weak Separability. Macroeconomic Dynamics, pp. 317-334.

Barnett, W.A. and A. Serletis (eds), 2000, The Theory of Monetary Aggregation, Contributions to Economic Analysis Monograph Series, Elsevier, Amsterdam.

Barnett, W.A. and W. Shu, 2005, On user costs of risky monetary assets. Annals of Finance 1, 35-50.

Barnett, W.A. and H. Xu, 1998, Stochastic Volatility in Interest Rates and Nonlinearity in Velocity. International Journal of Systems Science 29, 1189-1201.

Barnett, W.A. and G. Zhou, 1994a, Partition of M2+ as a Joint Product: Commentary, Federal Reserve Bank of St. Louis Review 76, 53-62.

Barnett, W.A. and G. Zhou, 1994b, Financial Firm's Production and Supply-Side Monetary Aggregation under Dynamic Uncertainty. Federal Reserve Bank of St. Louis Review, March/April, 133-165. Reprinted in W.A. Barnett and J. Binner, (Eds.), 2004, Functional Structure and Approximation in Econometrics, North Holland, Amsterdam, ch. 16, pp. 381-427.

Barnett, W.A., U. Chae, and J. Keating, 2006, The Discounted Economic Stock of Money with VAR Forecasting. Annals of Finance 2, 2, 229-258.

Barnett, William A, M. Chauvet, and H.L.R. Tierney, 2009, Measurement Error in Monetary Aggregates: A Markov Switching Factor Approach, Macroeconomic Dynamics 13, Supplement 2, 381-412. 
Barnett, W.A, M.J. Hinich, and W.E. Weber, 1986, The Regulatory Wedge between the Demand-Side and Supply-Side Aggregation-Theoretic Monetary Aggregates. Journal of Econometrics 33, 165-185. Reprinted in W.A. Barnett and A. Serletis, (Eds.), 2000, The Theory of Monetary Aggregation, North Holland, Amsterdam, ch. 19, pp. 433-453.

Barnett, W., Fisher, D. and A. Serletis, 1992, Consumer Theory and the Demand for Money. Journal of Economic Literature 30, 2086-119. Reprinted in Barnett and Serletis (2000, ch. 18, pp. 389-427).

Barnett, W.A., Y. Liu, and M. Jensen, 1997, “CAPM Risk Adjustment for Exact Aggregation over Financial Assets," Macroeconomic Dynamics 1, 485-512.

Barnett, W.A., E.K. Offenbacher, and P.A. Spindt, 1984, The New Divisia Monetary Aggregates. Journal of Political Economy 92, 1049-1085. Reprinted in W.A. Barnett and A. Serletis (eds.), 2000, The Theory of Monetary Aggregation, North Holland, Amsterdam, ch. 17, pp. 360-388.

Batchelor, R., 1989. A Monetary Services Index for the UK, Mimeo, Department of Economics, City University, London.

Belongia, M., 1996, Measurement Matters: Recent Results from Monetary Economics Reexamined. Journal of Political Economy 104, 5, 1065-1083.

Belongia, M. and J. Binner, (Eds), 2000, Divisia Monetary Aggregates: Theory and Practice. Basingstoke: Palgrave.

Belongia, M. and A. Chrystal, 1991, An Admissible Monetary Aggregate for the United Kingdom. Review of Economics and Statistics 73, 497-503.

Belongia, M. and P. Ireland, 2006, The Own-Price of Money and the Channels of Monetary Transmission. Journal of Money Credit and Banking 38, 2, 429-445.

Belongia, M. and P. Ireland, 2010, The Barnett Critique After Three Decades: A New Keynesian Analysis, Journal of Econometrics, forthcoming. 
Bernanke, B., 2006, Monetary Aggregates and Monetary Policy at the Federal Reserve: A Historical Perspective, Speech at the Fourth ECB Central Banking Conference, Frankfurt, Germany, November.

Chauvet, M., 1998, An Econometric Characterization of Business Cycle Dynamics with Factor Structure and Regime Switches. International Economic Review 39, 4, 969-96.

Chauvet, M., 2001, A Monthly Indicator of Brazilian GDP. Brazilian Review of Econometrics 21, 1, 1-15.

Chauvet, M. and J. Piger, 2008, A Comparison of the Real-Time Performance of Business Cycle Dating Methods. Journal of Business Economics and Statistics 26, 1, 42-49.

Chetty, K. V., 1969, On Measuring the Nearness of Near-Moneys. American Economic Review 59, 270281.

Chrystal, A. and R. MacDonald, 1994, Empirical Evidence on the Recent Behaviour and Usefulness of Simple-Sum and Weighted Measures of the Money Stock. Federal Reserve Bank of St. Louis Review 76, 73-109.

Cockerline, J. and J. Murray, 1981, A Comparison of Alternative Methods for Monetary Aggregation: Some Preliminary Evidence. Technical Report \#28, Bank of Canada.

Deaton, A. and J. N. Muellbauer, 1980, Economics and Consumer Behavior. Cambridge, Cambridge University Press.

Diewert, W. E., 1974, Intertemporal Consumer Theory and the Demand for Durables. Econometrica 42, 497-516.

Diewert, W. E., 1976, Exact and Superlative Index Numbers. Journal of Econometrics, 4, 115-45.

Diewert, W. E., 1978, Superlative Index Numbers and Consistency in Aggregation. Econometrica 46, 883900.

Divisia, F., 1925, L'Indice monétaire et la théorie de la monnaie. Revue d'Economie Politique 39, 9801008. 
Donovan, D., 1978, Modeling the Demand for Liquid Assets: An Application to Canada. IMF Staff Papers, 25, 676-704.

Drake, L., 1992. The Substitutability of Financial Assets in the U.K. and the Implication for Monetary Aggregation. Manchester School of Economics and Social Studies 60, 221-248.

Fase, M., 1985. Monetary Control: The Dutch Experience: Some Reflections on the Liquidity Ratio, in: Monetary Conditions for Economic Recovery, C. van Ewijk and J. J. Klant, (Eds.), Dordrecht: Martinus Nijhoff, pp. 95-125.

Feenstra, Robert C., 1986, Functional Equivalence between Liquidity Costs and the Utility of Money. Journal of Monetary Economics 17:2, 271-291.

Fisher, I., 1922, The Making of Index Numbers: A Study of their Varieties, Tests, and Reliability, Boston: Houghton Mifflin.

Friedman, M. and A. Schwartz, 1970, Monetary Statistics of the United States: Estimation, Sources, Methods, and Data, Columbia University Press, New York.

Goldfeld, S.M., 1973, The Demand for Money Revisited. Brookings Papers on Economic Activity 3, 577638.

Hancock, D., 1985a, Bank Profitability, Interest Rates, and Monetary Policy. Journal of Money, Credit and Banking 17, 189-202.

Hancock, D., 1985b, The Financial Firm: Production with Monetary and Nonmonetary Goods. Journal of Political Economy 93, 859-80.

Hancock, D., A Theory of Production for the Financial Firm. Norwell, Massachusetts: Kluwer Academic Publishers, 1991.

Hicks, J.R., 1946, Value and Capital, Clarendon Press, Oxford.

Hoa, T.V, 1985, A Divisia System Approach to Modelling Monetary Aggregates. Economics Letters 17, 365-368. 
Hutt, W. H, 1963, Keynesianism - Retrospect and Prospect. Regnery, Chicago.

International Monetary Fund, Monetary and Financial Statistics: Compilation Guide. International Monetary Fund Publication Services, Washington, DC, 2008, 183-184.

Ishida, K., 1984. Divisia Monetary Aggregates and the Demand for Money: A Japanese Case. Bank of Japan Monetary and Economic Studies 2, 49-80.

Jones, B., D. Dutkowsky, and T. Elger, 2005, Sweep Programs and Optimal Monetary Aggregation. Journal of Banking and Finance 29, 483-508.

Lucas, R.E., 2000, Inflation and Welfare. Econometrica 68, 62, 247-274.

Rotemberg, J. J., J. C. Driscoll, and J. M. Poterba, 1995, Money, Output, and Prices: Evidence from a New Monetary Aggregate. Journal of Business and Economic Statistics 13, 67-83.

Rayton, B. A. and K. Pavlyk, 2010, On the Recent Divergence between Measures of the Money Supply in the UK. Economics Letter 108, August, 159-162.

Serletis, A. (ed.), 2006, Money and the Economy, World Scientific.

Schunk, D., 2001, The Relative Forecasting Performance of the Divisia and Simple Sum Monetary Aggregates. Journal of Money, Credit and Banking 33, 2, 272-283.

Swamy, P.A.V.B. and P. Tinsley, 1980, Linear Prediction and Estimation Methods for Regression Models with Stationary Stochastic Coefficients. Journal of Econometrics 12, 103-42.

Yue, P. and R. Fluri, 1991, Divisia Monetary Services Indexes for Switzerland: Are They Useful for Monetary Targeting? Federal Reserve Bank of St. Louis Review 73, 19-33.

Table 1: Mean Growth Rates During the Period November 1979 to August 1982

\section{Monetary Aggregate}

Divisia M2

Simple Sum M2

\section{Mean Growth Rate}

\section{5}

9.3 
Divisia M3

Simple Sum M3
4.8

10.0

Figure 1: Demand Side Aggregation Error Range

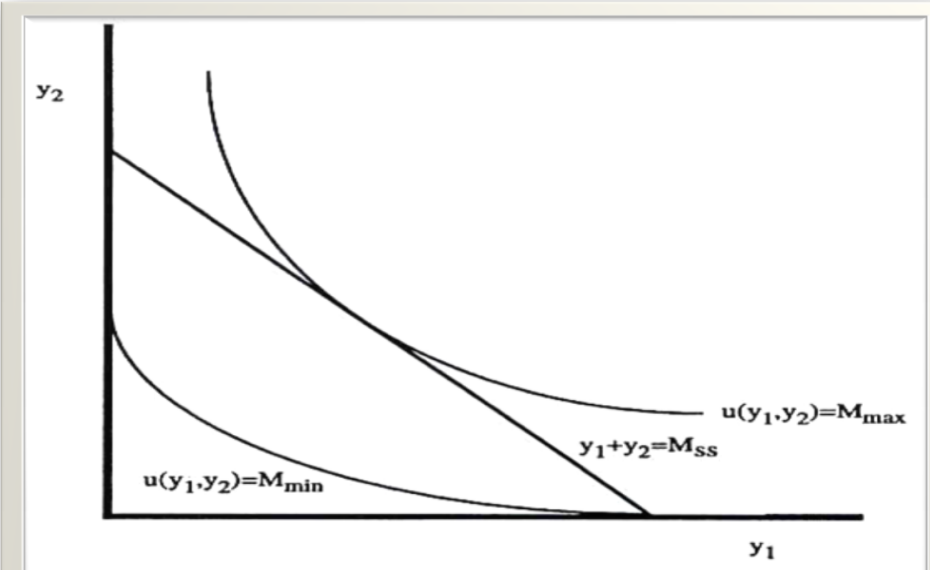

Figure 2: Seasonally adjusted normalized velocity during the 1970 s

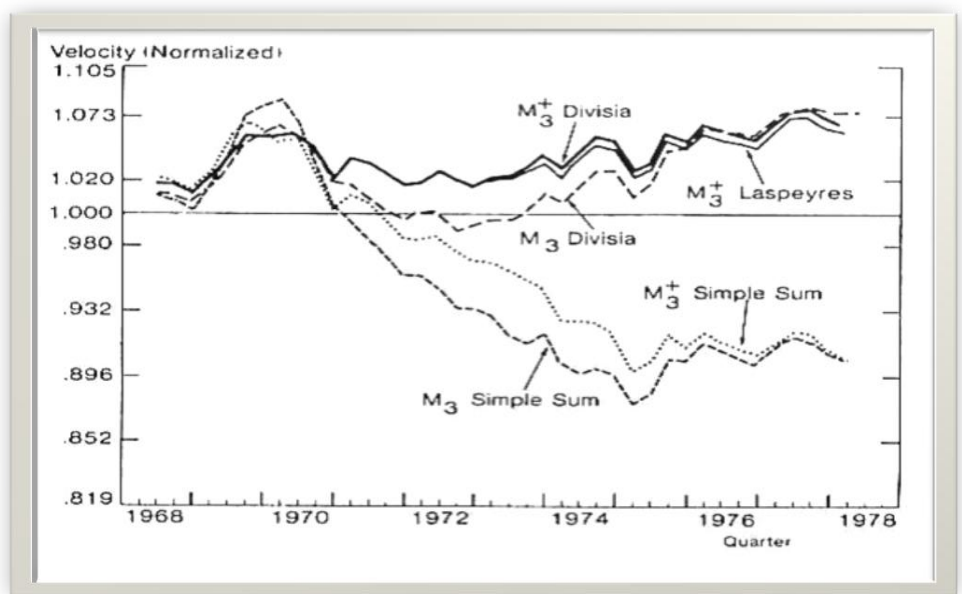

Figure 3: Interest Rates during the 1970s: 10 year government bond rate 


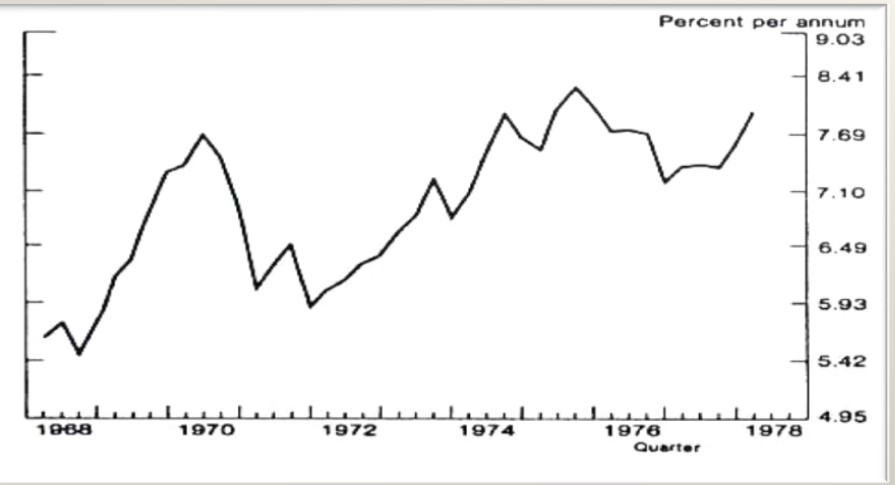

Figure 4: Simple Sum M3 Velocity versus Interest Rate: Moody's AAA corporate bond rate, quarterly,1959.1-19980.3

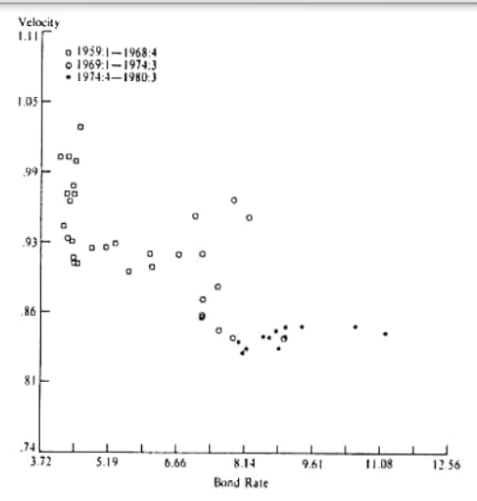

Figure 5: Divisia M3 Velocity versus Interest Rate: Moody’s AAA corporate bond rate, quarterly, 1959.1-19980.3

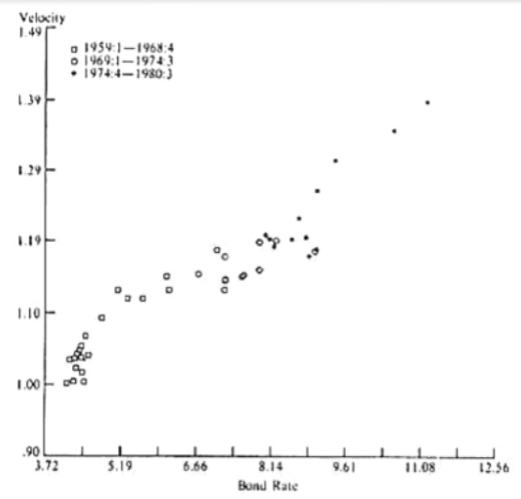

Figure 6: Simple Sum M3 Base Multiplier versus Interest Rate: deviation from time trend of Moody's Baa corporate bond rate, monthly 1969.1-1981.8. 


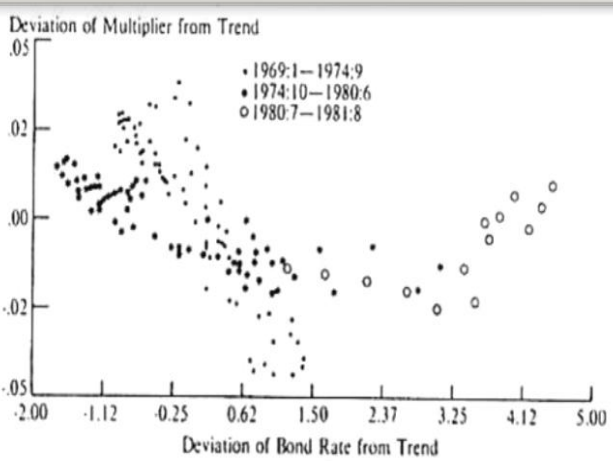

Figure 7: Divisia M3 Monetary Aggregate Base Multiplier versus Deviation from time trend of Moody's Baa corporate bond Interest Rate, monthly 1969.1-1981-8.

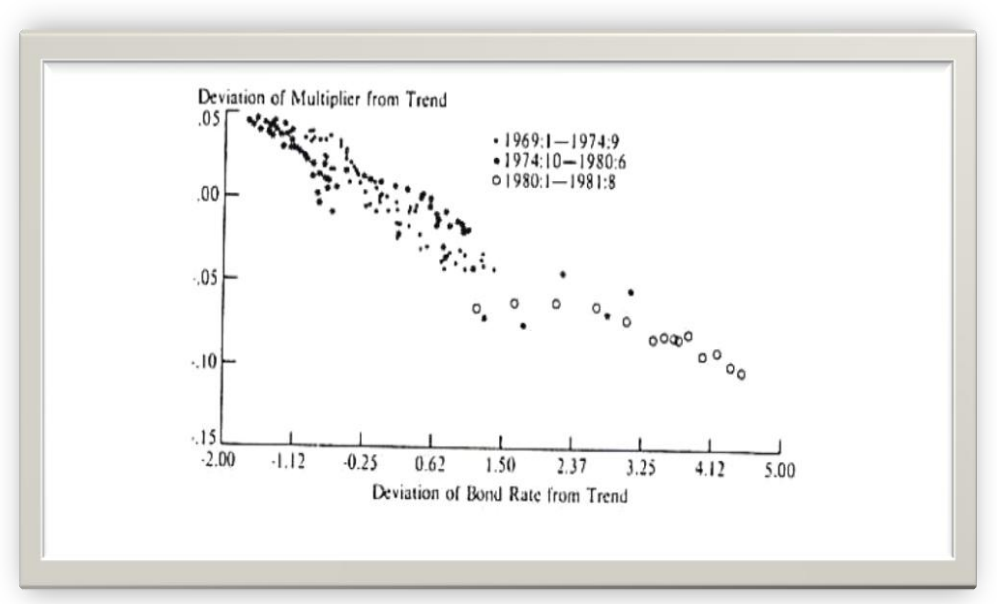

Figure 8: Income Coefficient Time Path

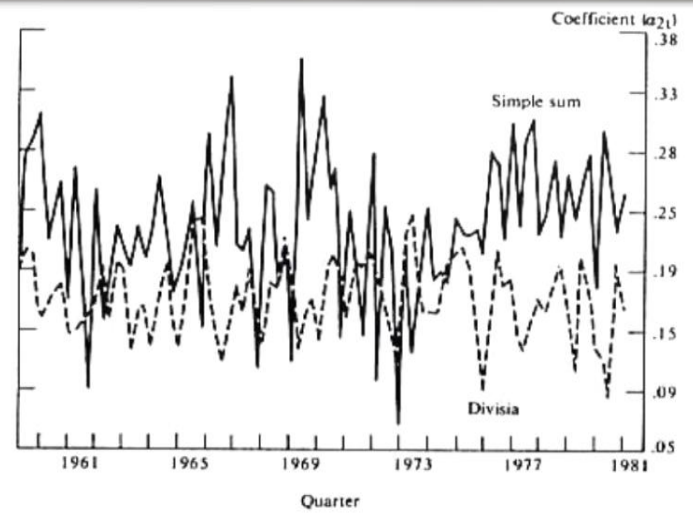

Figure 9: Market Interest Rate (commercial paper rate) Coefficient Time Path 


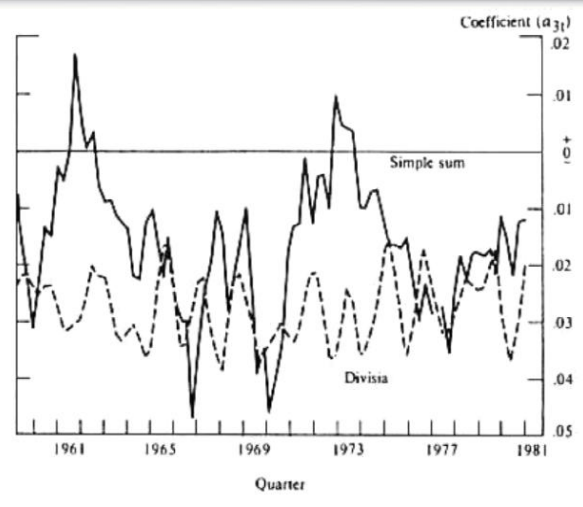

Figure 10: Regulated Interest Rate (passbook rate) Coefficient Time Path

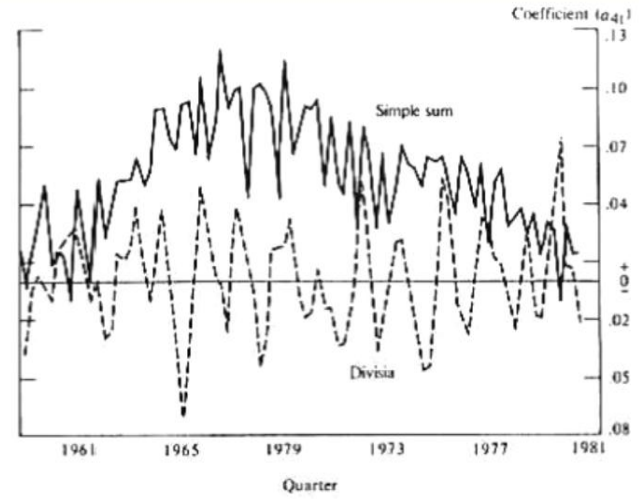

Figure 11: Seasonally adjusted annual M3 Growth Rates. Divisia (-), simple sum (---). The last three observations to the right of the vertical line are post sample period.

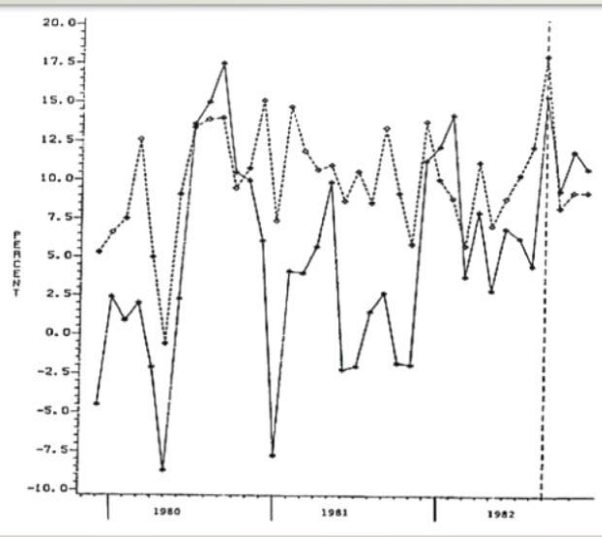


Figure 12: Monetary Growth Rates, 1970-1996, from St. Louis Federal Reserve's Database

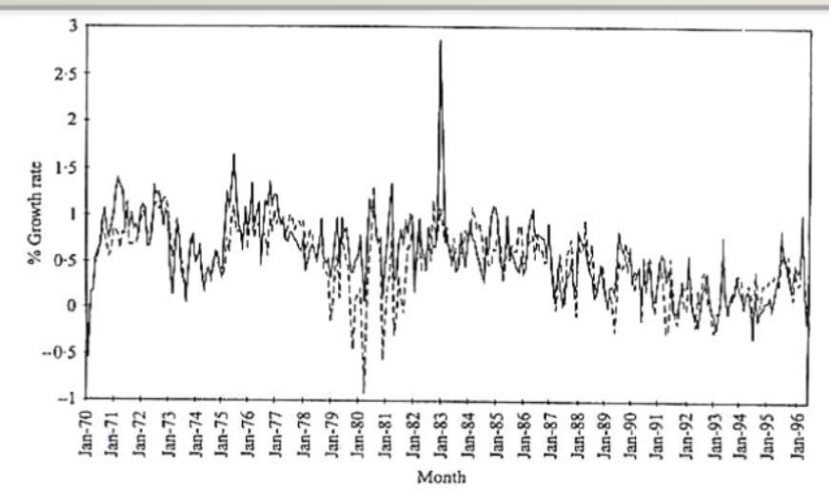

Figure 13. Simulated velocity slope coefficient with stochastic volatility of interest rates

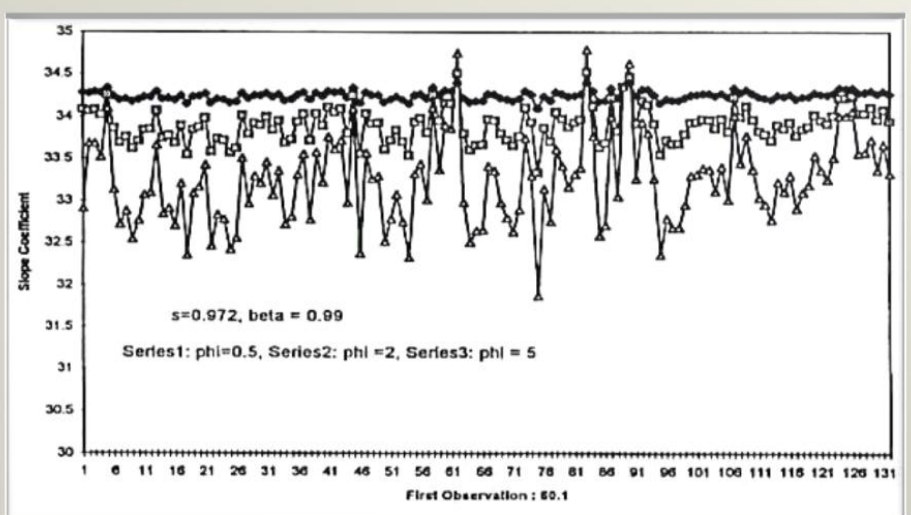

Figure 14: M2 Joint Product and Economic Capital Stock of Money. M2=simple sum joint product; $\mathrm{CEM} 2=$ economic capital stock part of the joint product.

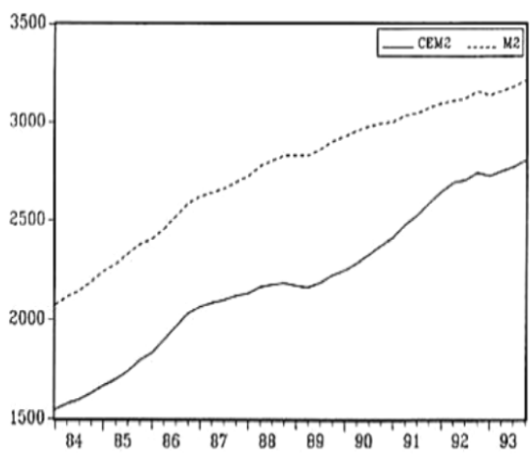


Figure 15: M2+ Joint Product and Economic Capital Stock of Money. M2+=simple sum joint product; CEM2+=economic capital stock part of the joint product.

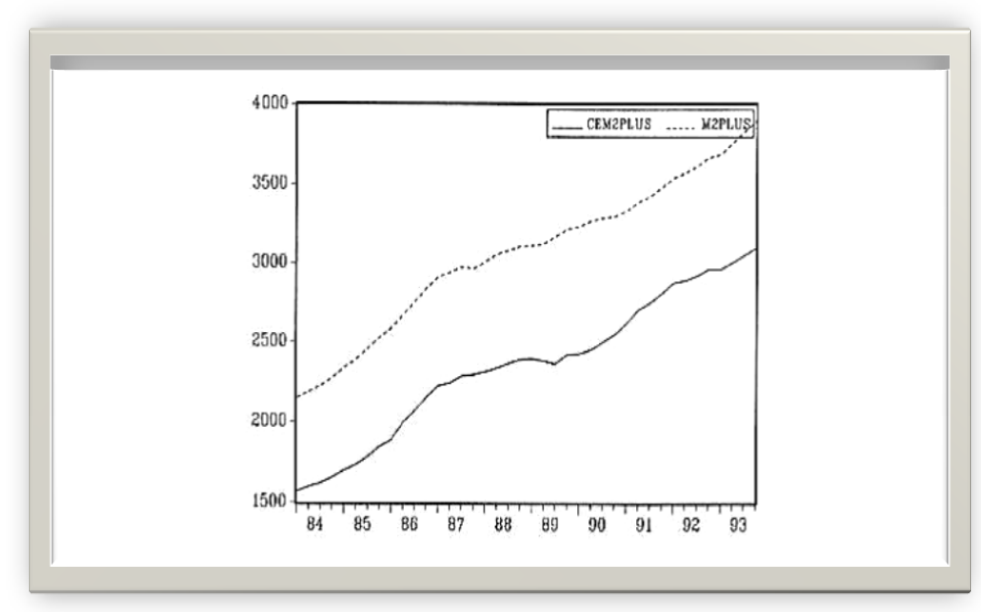

Figure 16: Monetary Base Surge

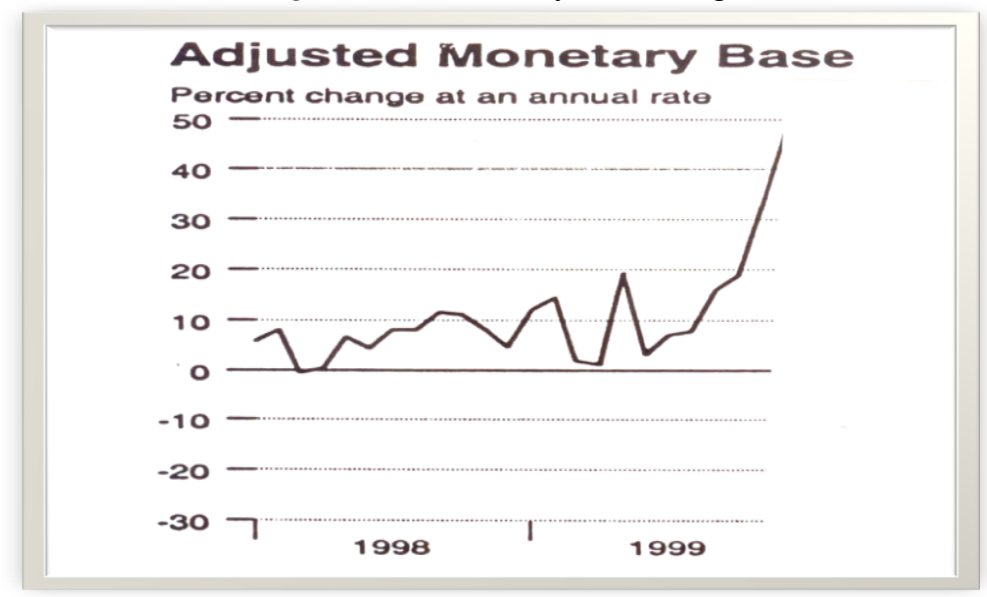

Figure 17: Y2K Computer Bug

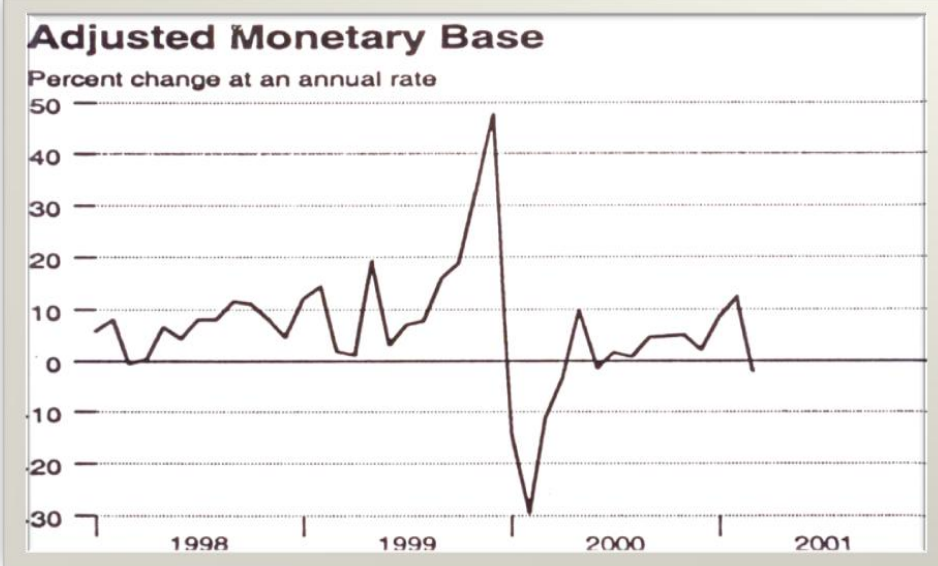


Figure 18: Financial General Equilibrium without Required Reserves

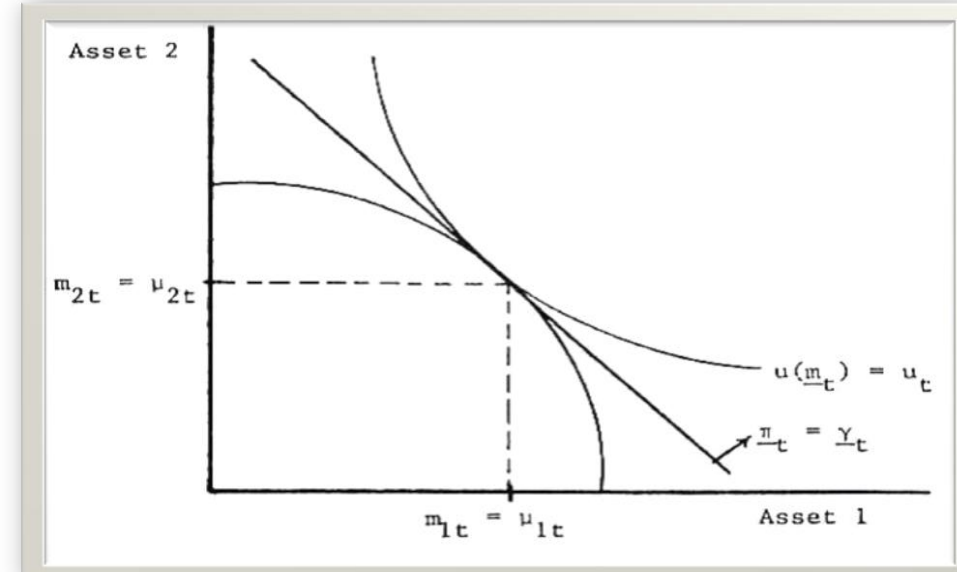

Figure 19: Financial Equilibrium with Positive Required Reserves

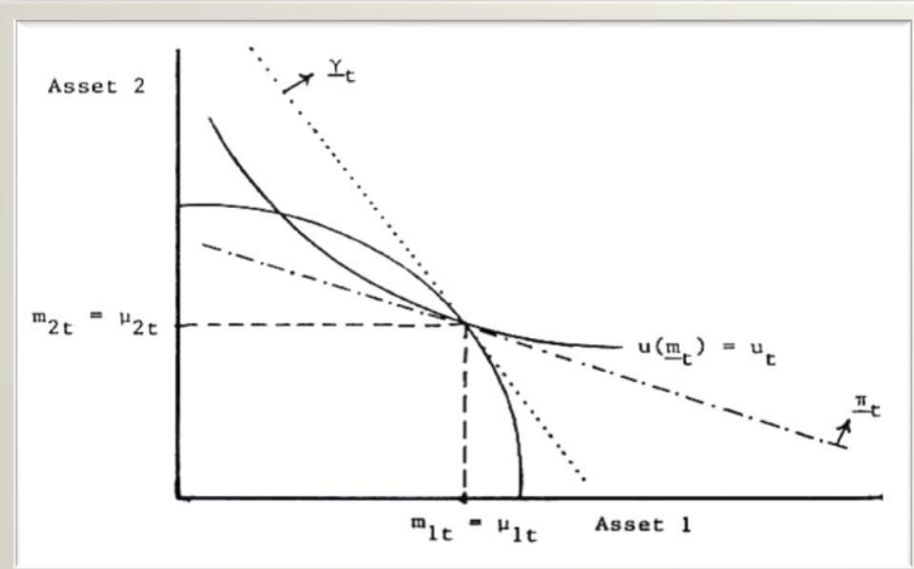

Figure 20: Squared Coherence between Divisia Demand and Supply Side Divisia

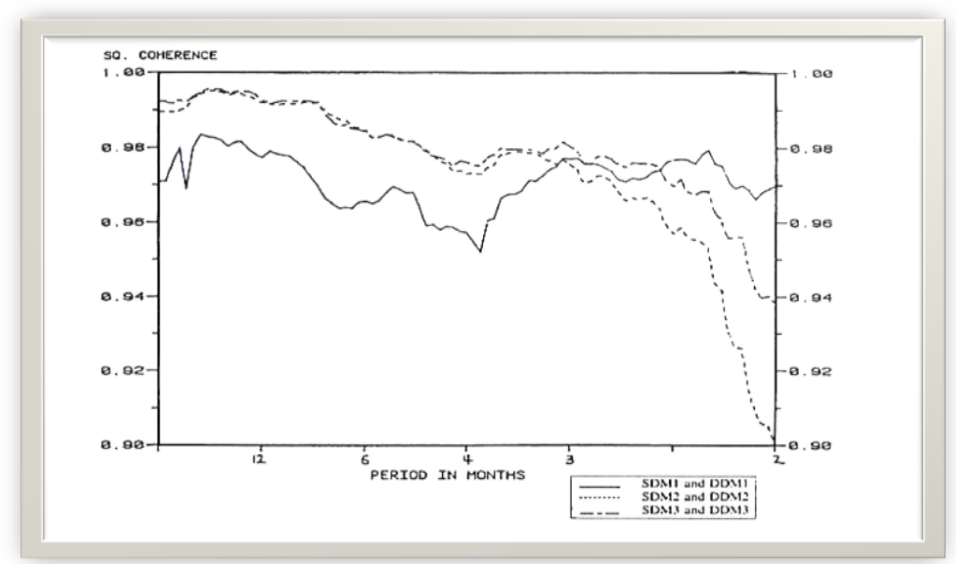


Figure 21: Simple sum M3, Divisia demand DDM3, and Divisia supply SDM3

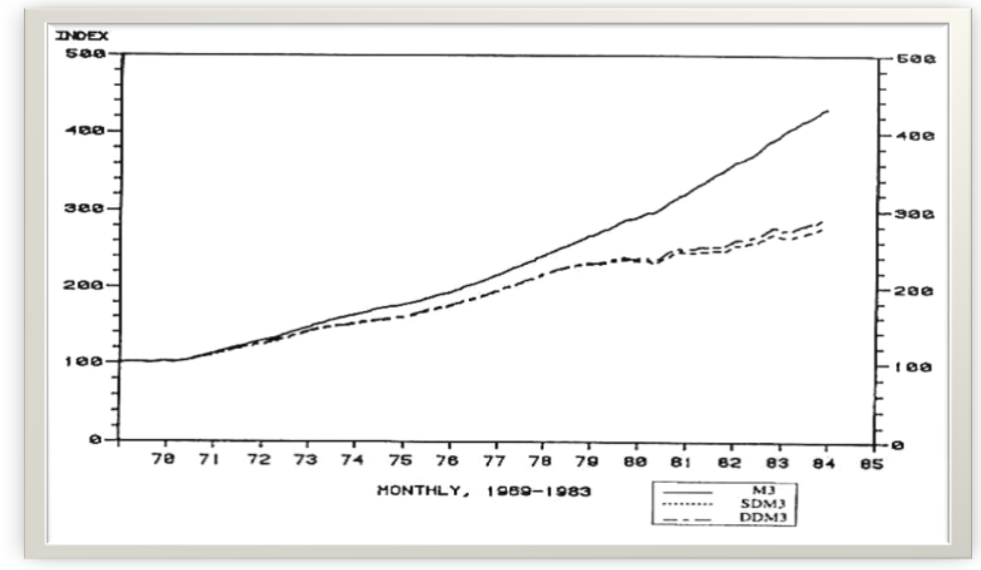

Figure 22: Idiosyncratic terms for M3 growth (---), Divisia M3 growth (-), difference between Divisia M3 growth and Simple Sum M3 growth (--), and NBER Recessions (shaded area)

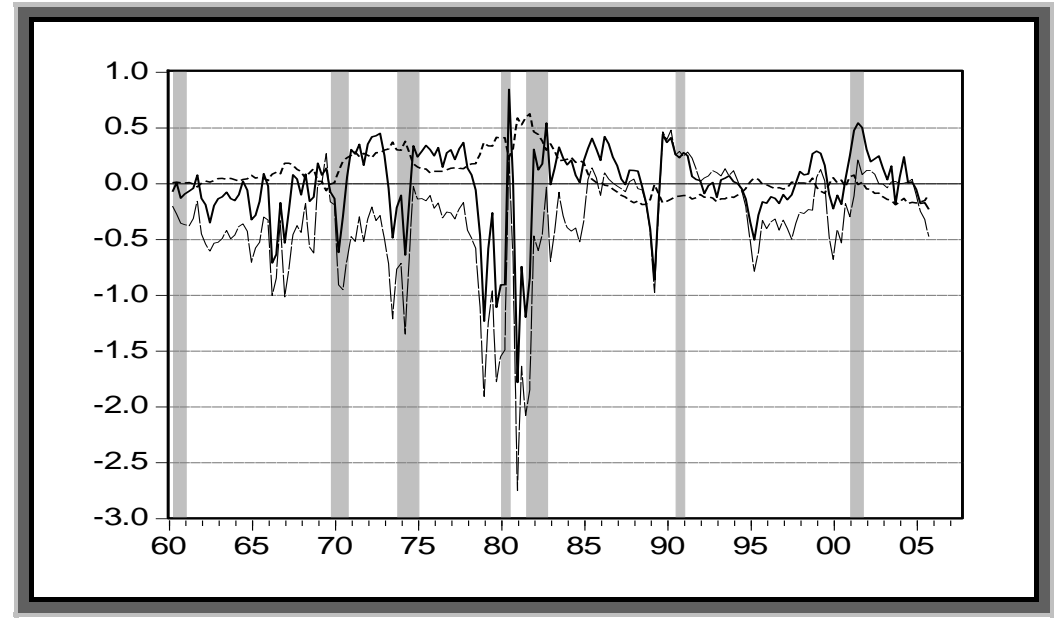

Figure 23: Idiosyncratic terms for M3 growth (---), Divisia M3 growth (-), difference between Divisia M3

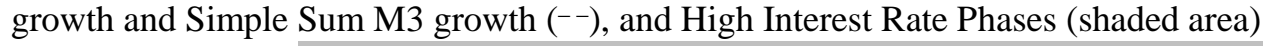

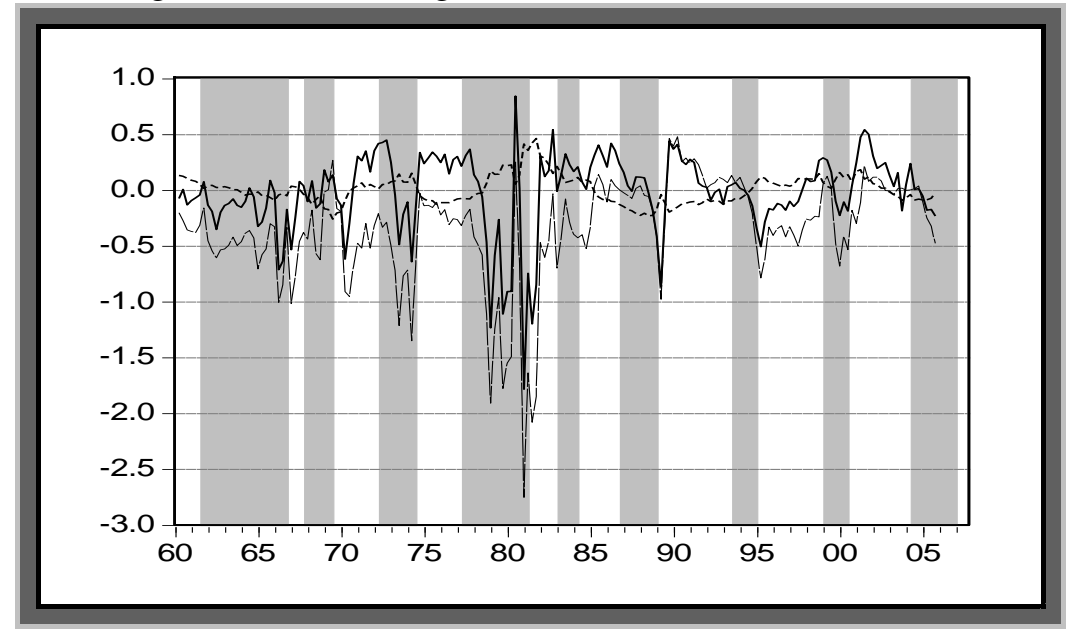


Figure 24: Idiosyncratic terms for M2 growth (---), Divisia M2 growth (-), difference between Divisia M2 growth and Simple Sum M2 growth (--), and NBER Recession (shaded area)

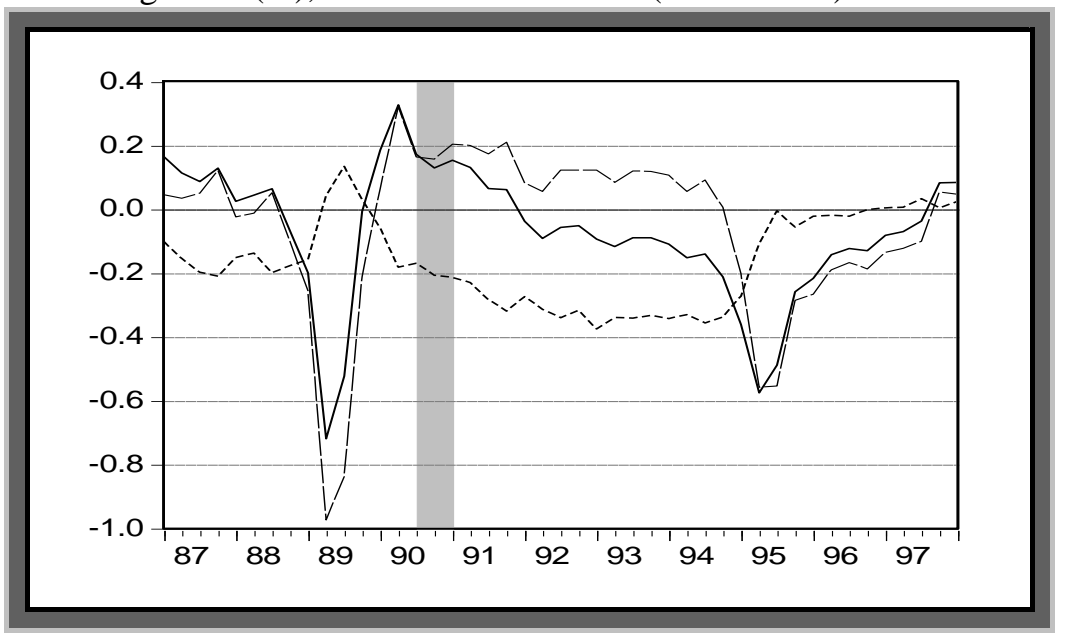

Figure 25: Idiosyncratic terms for M3 growth (---), Divisia M3 growth (-), difference between Divisia M3 growth and Simple Sum M3 growth $\left({ }^{-}\right)$
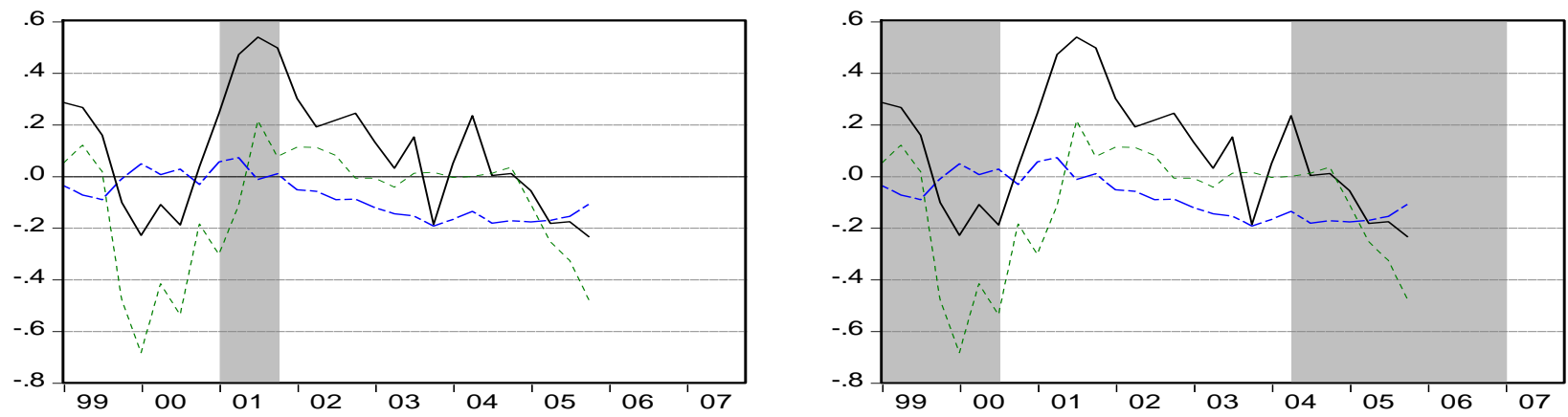

Figure 26: Total Reserves Until Very Recently

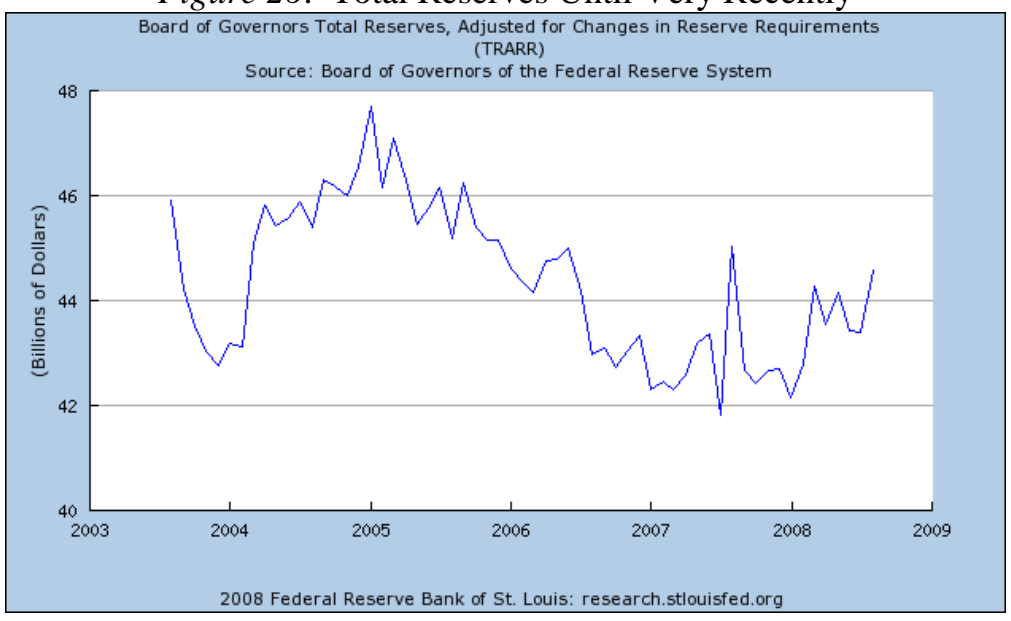


Figure 27: Total Reserves Including Recent Surge Board of Governors Total Reserves, Adjusted for Changes in Reserve Requirements

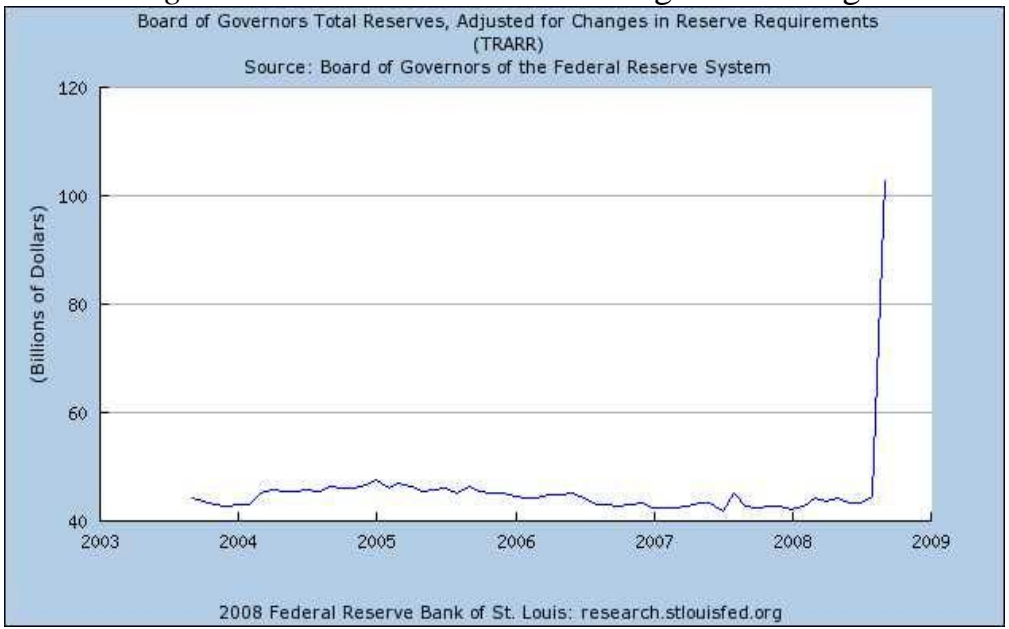

Figure 28: Taylor Rule Federal Funds Rate

Monetary Trends

updated through $05 / 01 / 08$

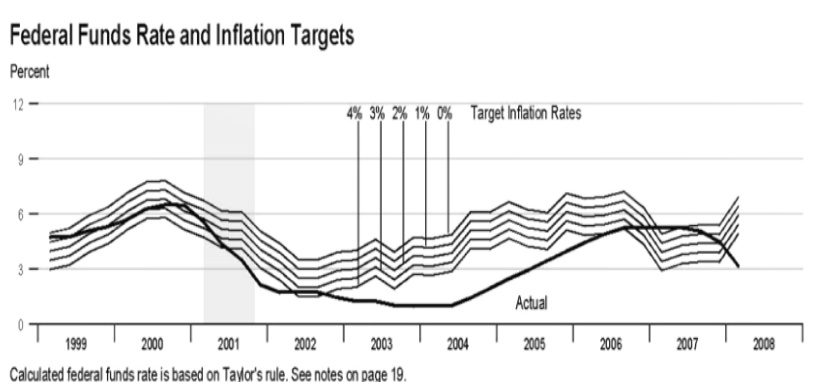

Calculted federal iunds rate is based on Taylor's rule. See notes on page 19.

Figure 29: Nonborrowed Reserves

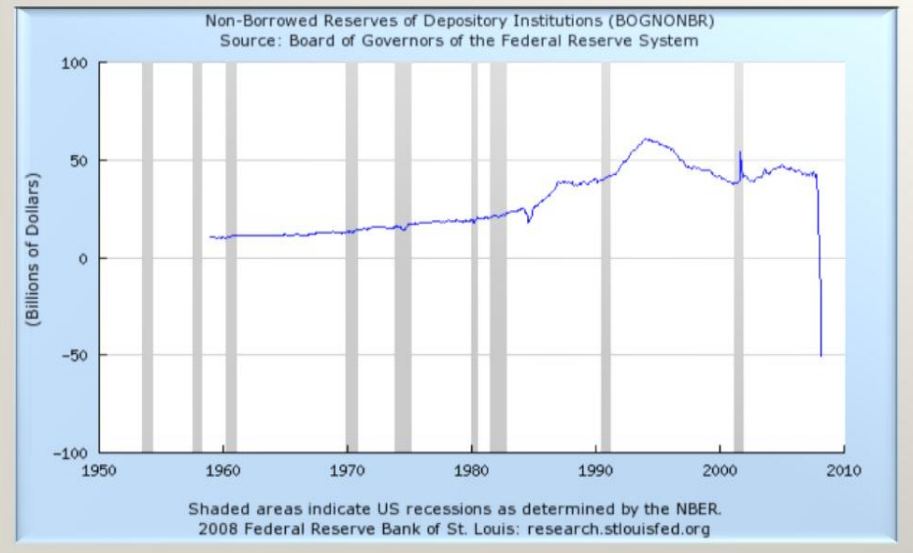


Figure 30: Growth in M4 Simple Sum (---) and M4 Divisia Aggregate (-) for the UK

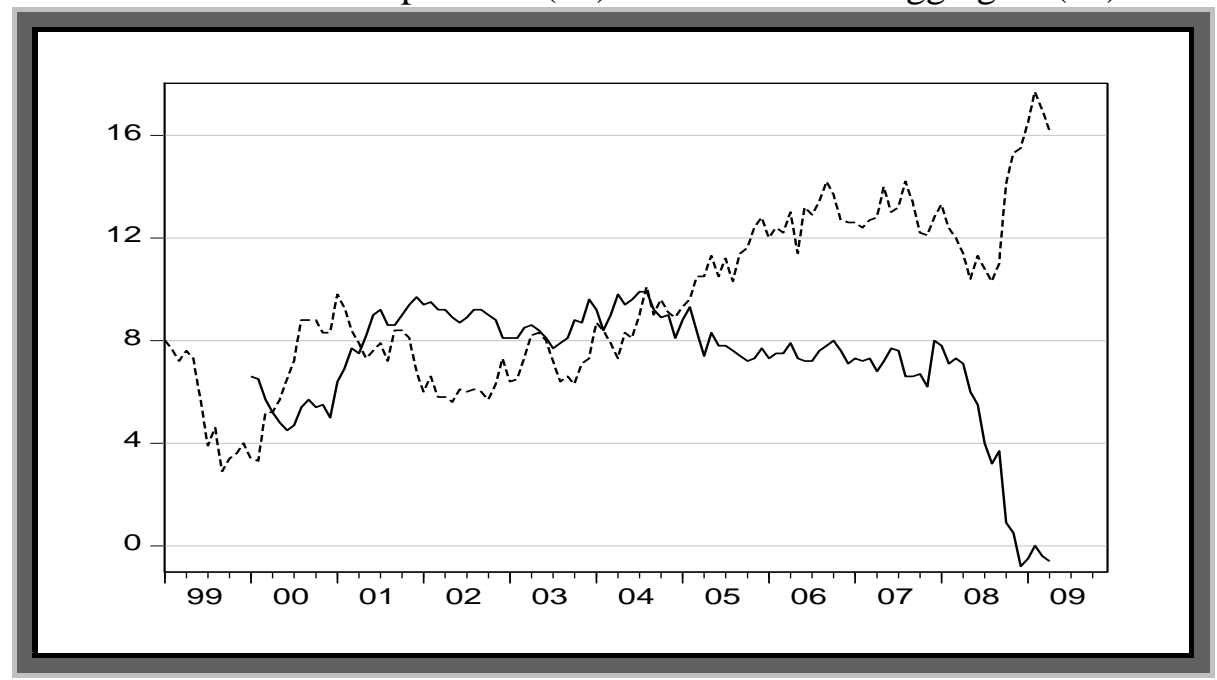

